\title{
Kidney Exchange
}

\section{Citation}

Roth, Alvin E., Tayfun Sönmez and M. Utku Ünver. 2004. Kidney exchange. Quarterly Journal of Economics 119(2): 457-488.

\section{Published Version}

http://dx.doi.org/10.1162/0033553041382157

\section{Permanent link}

http://nrs.harvard.edu/urn-3:HUL.InstRepos:2580565

\section{Terms of Use}

This article was downloaded from Harvard University's DASH repository, and is made available under the terms and conditions applicable to Other Posted Material, as set forth at http:// nrs.harvard.edu/urn-3:HUL.InstRepos:dash.current.terms-of-use\#LAA

\section{Share Your Story}

The Harvard community has made this article openly available.

Please share how this access benefits you. Submit a story.

\section{Accessibility}




\title{
Kidney Exchange*
}

\author{
Alvin E. Roth ${ }^{\dagger}$ \\ Tayfun Sönmez \\ M. Utku Ünver ${ }^{\S}$ \\ Harvard University \\ Koç University \\ Koç University
}

August 2003 / Revised: January 2004

forthcoming in the Quarterly Journal of Economics

\begin{abstract}
Most transplanted kidneys are from cadavers, but there are also many transplants from live donors. Recently, there have started to be kidney exchanges involving two donor-patient pairs such that each donor cannot give a kidney to the intended recipient because of immunological incompatibility, but each patient can receive a kidney from the other donor. Exchanges are also made in which a donor-patient pair makes a donation to someone waiting for a cadaver kidney, in return for the patient in the pair receiving high priority for a compatible cadaver kidney when one becomes available. There are stringent legal/ethical constraints on how exchanges can be conducted. We explore how larger scale exchanges of these kinds can be arranged efficiently and incentive compatibly, within existing constraints. The problem resembles some of the "housing" problems studied in the mechanism design literature for indivisible goods, with the novel feature that while live donor kidneys can be assigned simultaneously, cadaver kidneys cannot. In addition to studying the theoretical properties of the proposed kidney exchange, we present simulation results suggesting that the welfare gains from larger scale exchange would be substantial, both in increased number of feasible live donation transplants, and in improved match quality of transplanted kidneys.
\end{abstract}

${ }^{*}$ We thank Muriel Niederle, Erhan Sönmez, Stefanos Zenios, and the participants of the SITE 2003 Workshop on Matching Markets for their insightful comments and Hüseyin Çankaya for his help with the figures. After a first draft of this paper was completed, we also benefited from many helpful conversations with Dr. Frank Delmonico of the New England Organ Bank. Sönmez gratefully acknowledges the research support of KoçBank via the KoçBank scholar program and Turkish Academy of Sciences in the framework of the Young Scientist Award Program via grant TS/TÜBA-GEBİ/2002-1-19. We also received support from an NSF grant through the NBER. All errors are our own responsibility.

${ }^{\dagger}$ E-mail: aroth@hbs.edu; address: Harvard University, Department of Economics, Cambridge, MA 02138 and Harvard Business School, Boston, MA 02163.

${ }^{\ddagger}$ E-mail: tsonmez@ku.edu.tr; address: Koç University, Department of Economics, College of Administrative Sciences and Economics, Rumeli Feneri Yolu, Sariyer, İstanbul, 34450, Turkey.

${ }^{\S}$ E-mail: uunver@ku.edu.tr; address: Koç University, Department of Economics, College of Administrative Sciences and Economics, Rumeli Feneri Yolu, Sarıyer, İstanbul, 34450, Turkey. 


\section{Introduction}

Transplantation is the preferred treatment for the most serious forms of kidney disease. There are over 55,000 patients on the waiting list for cadaver kidneys in the U.S., of whom almost 15,000 have been waiting more than three years. By way of comparison, in 2002 there were over 8,000 transplants of cadaver kidneys performed in the U.S. In the same year, about 3,400 patients died while on the waiting list, and another 900 became too ill to be eligible for transplantation. In addition to transplants of cadaver kidneys, in 2002 there were also somewhat over 6,000 transplants of kidneys from living donors, a number that has been increasing steadily from year to year. See Table 1.

There is thus a considerable shortage of kidneys, compared to the demand. However, the substantial consensus in the medical community remains firmly opposed to allowing organseven cadaveric organs-to be bought and sold, and this is a felony under the National Organ Transplant Act (NOTA) of 1984, and the Uniform Anatomical Gift Act of 1987. ${ }^{1}$ ) The present paper considers ways to alleviate this shortage, and improve patient welfare, within the constraints of the current social and legal environment.

The National Organ Transplant Act of 1984 established the Organ Procurement and Transplantation Network (OPTN). Run by the United Network for Organ Sharing (UNOS), it has developed a centralized priority mechanism for the allocation of cadaveric kidneys.

Transplants from live donors generally have a higher chance of success than those from cadavers. The way such transplants are typically arranged is that a patient identifies a healthy willing donor (a spouse, for example) and, if the transplant is feasible on medical grounds, it is carried out. If the transplant from the willing donor is not feasible, the patient typically enters (or remains on) the queue for a cadaver kidney, while the donor returns home.

Recently, however, in a small number of cases, additional possibilities have been utilized when a transplant from a live donor and the intended recipient is infeasible. One of these, called a paired exchange, involves two patient-donor couples, for each of whom a transplant from donor to intended recipient is infeasible, but such that the patient in each couple could feasibly receive a transplant from the donor in the other couple (Rapaport [1986], Ross et al. [1997]). This pair of couples can then exchange donated kidneys. Compared to receiving cadaver kidneys at an unknown future time, this improves the welfare of the patients. In addition, it relieves the demand on the supply of cadaver kidneys, and thus potentially improves the welfare of those patients on the cadaver queue. A small number of these two-couple operations have been done, and the transplantation community has issued a consensus statement declaring them to

\footnotetext{
${ }^{1}$ There is, however, a steady stream of literature both by doctors and by economists, considering how the shortage of organs might be alleviated by allowing their purchase and sale, and what effects this might have. See e.g. Nelson et al. [1993] for an argument in favor of the status quo, and e.g. Becker \& Elias [2002] for an argument in favor of a market. Recent Congressional testimony endorsing the status quo but suggesting that empirical investigation of financial incentives might be in order can be found in Slade [2003].
} 
be ethically acceptable (Abecassis et al. [2000]). ${ }^{2}$

Another possibility is an indirect exchange (or list exchange) involving an exchange between one incompatible patient-donor couple, and the cadaver queue (Ross \& Woodle [2000]). In this kind of exchange, the patient in the couple receives high priority on the cadaver queue, in return for the donation of his donor's kidney to someone on the queue. ${ }^{3}$ This improves the welfare of the patient in the couple, compared to having a long wait for a suitable cadaver kidney, and it benefits the recipient of the live kidney, and others on the queue who benefit from the increase in kidney supply due to an additional living donor. However Ross and Woodle note that his may have a negative impact on type $\mathrm{O}$ patients already on the cadaver queue, an issue studied by Zenios, Woodle, \& Ross [2001], to which we shall return.

In contrast to the system for cadaveric organs, and despite the growing interest in at least small scale exchanges involving living donors, there is no national system, or even an organized registry at any level, for managing exchanges of kidneys from live donors. However, individual hospitals are beginning to think about larger scale living donor exchanges. As this paper was being written, the first three-couple kidney transplant exchange in the United States was reported at Johns Hopkins Comprehensive Transplant Center in Baltimore, among three couples for whom no two-couple transfer was feasible (Olson, August 2, 2003). In the present paper we will consider how such a system of exchanges might be organized, from the point of view of achieving efficiency, and providing consistent incentives to patients, donors, and doctors, and what its welfare implications might be. We will see that the benefits of wider exchange accrue not only to the parties to the exchange. The resulting increase in live organ donation also benefits patients waiting for cadaver kidneys, including type $\mathrm{O}$ patients. The design we propose is partly inspired by the mechanism design literature on "house allocation," and is intended to build on and complement the existing practices in kidney transplantation. In this respect and others it is in the modern tradition of engineering economics (see Roth [2002]) as applied to other problems of allocation, such as labor market clearinghouses (see Roth \& Peranson [1999]), or auctions (see Milgrom [forthcoming]), in which practical implementation often involves incremental change in existing practices.

\section{Background}

Kidney Transplantation: End Stage Renal Disease (ESRD) is a fatal disease unless treated with dialysis or kidney transplantation. Transplantation is the preferred treatment. Two ge-

\footnotetext{
${ }^{2}$ UNOS also published a legal opinion that such exchanges do not violate the NOTA (http://www.asts.org/ezefiles/UNOSSection_301_NOTA_pdf).

${ }^{3}$ Priority on the cadaver queue is actually a bit complex, as queues are organized regionally, and consist of multiple queues, on which priority is determined by a scoring rule that gives points for how well matched the available kidney is to each patient, how long the patient has been waiting, etc. Giving high priority on the queue could be implemented by giving an appropriate number of points in the scoring rule.
} 
netic characteristics play key roles in the feasibility and success of a kidney transplant. The first is the ABO blood-type: There are four blood types A, B, AB and O. Absent other complications, type $\mathrm{O}$ kidneys can be transplanted into any patient; type $\mathrm{A}$ or type $\mathrm{B}$ kidneys can be transplanted into same type or type AB patients; and type AB kidneys can only be transplanted into type $\mathrm{AB}$ patients. (So type $\mathrm{O}$ patients can only receive type $\mathrm{O}$ kidneys.) The second genetic characteristic is tissue type, also known as HLA type: HLA type is a combination of six proteins. As the HLA mismatch between the donor and the recipient increases, the likelihood of graft (i.e. transplanted organ) survival decreases (Opelz [1997]). HLA plays another key role in transplantation through the pre-transplant "crossmatch" test. Prior to transplantation, the potential recipient is tested for the presence of preformed antibodies against HLA in the donor kidney. The presence of antibodies, called a positive crossmatch, effectively rules out transplantation.

When a cadaveric kidney becomes available for transplantation, the priority of each patient on the waiting list is determined by a point system based on factors including the blood-type, HLA antigen-match, time spent on the waiting list, the region the kidney is harvested, etc. and the kidney is offered to the patient with the highest priority. If that patient declines, the kidney is offered to the patient with the next highest priority, and so on. Living donor kidney grafts have superior survival rates (and their availability can also avoid the long waiting time for a cadaver kidney). However potential living donors can be eliminated from consideration due to incompatibility of the potential donor kidney with the intended recipient.

To minimize the elimination of physically eligible volunteer kidney donors on the basis of immunologic incompatibilities, Rapaport [1986] proposed the creation of a living donor pool for paired exchange. Ross et al. [1997] again proposed to increase the supply of living kidney donations by using kidneys from living incompatible donors through an exchange arrangement between two pairs. In 2000, UNOS initiated pilot testing of such programs.

Another exchange program is the indirect exchange program (Ross \& Woodle [2000]): A potential donor who is incompatible with his intended recipient donates his kidney to the cadaveric waiting list and his paired recipient will receive priority for the next compatible cadaveric kidney. There is widespread agreement in the transplantation community that indirect exchange can harm type $\mathrm{O}$ patients who have no living donors. First, they will be losing their priority to type $\mathrm{O}$ patients whose incompatible donors donate to the cadaveric pool, and second, very few type $\mathrm{O}$ living kidneys will be offered to their pool since a type $\mathrm{O}$ donor can directly donate to his intended recipient unless there is a positive crossmatch. Despite this widespread concern, many transplant centers have also cautiously started pilot indirect exchange programs since 2000. For example, in UNOS Region 1 (New England), consisting of 14 transplant centers and 2 Organ Procurement Organizations, 4 paired exchanges and 17 indirect exchanges have been conducted from 2001 through 2003 (personal communication).

Mechanism Design: We will extend results in the mechanism design literature, which we first quickly review. Shapley \& Scarf [1974] modeled a "housing market" consisting of n agents each 
of whom is endowed with an indivisible good, a "house." Each agent has preferences over all the houses, and there is no money in the market, trade is feasible only in houses. They attribute to David Gale the "top trading cycle" algorithm that produces a house allocation in the core of the market. The algorithm works as follows: Each agent points to her most preferred house (and each house points to its owner). There is at least one cycle in the resulting directed graph. In each such cycle, the corresponding trades are carried out, i.e. each agent in the cycle receives the house she is pointing to, and these agents and houses are removed from the market. The process continues (with each agent pointing to her most preferred house that remains on the market) until no agents remain, and the final allocation is the one in which each agent receives the house with which she left the market. When all preferences are strict, the procedure yields a unique outcome (Roth \& Postlewaite [1977]) and truthful preference revelation is a dominant strategy (Roth [1982]).

Note that paired kidney exchanges similarly seek the gains from trade among patients with willing donors, but (with the recent Johns Hopkins 3-pair exchange being a notable exception) mostly among just two pairs. In the kidney exchange to be considered below, if we consider exchange only among patients with donors, the properties of the housing market model essentially carry over unchanged, if we assume that donors' preferences are aligned with those of their intended recipient. We will also assume that all surgeries in a given cycle are carried out simultaneously, which is the current practice, since a donor's willingness to donate a kidney might change once her intended recipient received a transplant.

However the kidney transplant environment consists not just of patients with donors, but also patients without donors, and cadaver kidneys not tied to any specific patient. Abdulkadiroğlu \& Sönmez [1999] studied housing allocation on college campuses, which is in some respects similar: A set of rooms must be allocated to a set of students by a centralized housing office. Some of the students are existing tenants each of whom already occupies a room and the rest of the students are newcomers. In addition to occupied rooms, there are vacant rooms. Existing tenants are entitled to keep their current rooms but may also apply for other rooms. Mechanisms used on a number of college campuses do not ensure the participation of existing tenants, and result in efficiency loss. This is the motivation for the generalization of the top trading cycles (TTC) mechanism proposed by Abdulkadiroğlu \& Sönmez [1999], which they called you request my house-I get your turn (YRMH-IGYT): Each student reports his strict preferences over all rooms and an ordering of agents is randomly chosen. For any given preference list and ordering, the outcome is obtained as follows: (1) Assign the first student his top choice, the second student his top choice among the remaining rooms, and so on, until someone requests the room of an existing tenant who is yet to be served. (2) Whenever that happens modify the remainder of the ordering by moving the existing tenant to the beginning of the line and proceed with the procedure. (3) If at any point a cycle forms, it is formed by exclusively existing tenants and each of them requests the room of the tenant who is next in the cycle. In such cases remove all students in the cycle by assigning them the rooms they 
request and proceed with the procedure. The key innovation here is that an existing tenant whose current room is requested is upgraded to the first place in the line of agents remaining unassigned, before his room is allocated. As a result the YRMH-IGYT mechanism assures every existing tenant a room that is no worse than his own. Therefore existing tenants do not have any reason not to enter the market and consequently the eventual allocation is Pareto efficient. Note that the idea of upgrading an existing tenant whose current room is requested to the top of the line was also invented by the transplantation community in the form of an indirect exchange program: When a potential donor donates his kidney to the highest priority patient in the waiting list, his intended recipient is upgraded to the top of the waiting list.

Note again that what prompted the introduction of simple kidney exchange programs was the loss of volunteer kidney donors because of immunologic incompatibilities. Under these exchange programs, a potential donor who is incompatible with his intended recipient is given the incentive to go ahead with the donation, because his donation makes it possible for his intended recipient to receive a compatible kidney. Similarly, the potential efficiency loss in the campus housing problem is that some rooms might fail to be traded, even when welfare enhancing trades are possible. The YRMH-IGYT is an attempt to address that problem in the housing context. We next consider how it must be adapted to kidney exchange.

\section{Kidney Exchange and the Top Trading Cycles and Chains (TTCC) Mechanism}

While there are clear similarities between house allocation and kidney exchange, there are also important differences. The counterpart of an existing tenant and his room is a donorrecipient pair, which we denote by $\left(k_{i}, t_{i}\right)$. We will often refer to donor $k_{i}$ as kidney $k_{i}$, and recipient $t_{i}$ as patient $t_{i}$. In the context of house allocation with existing tenants, there are also newcomers, none of whom owns a specific house, and vacant houses, none of which is owned by a specific student. The counterpart of newcomers are patients who have no living donors, and the counterpart of vacant houses are cadaveric kidneys which are not targeted for specific patients. This analogy reveals one important difference between the two models: In the house allocation model, the set of vacant houses is known. In the kidney exchange problem, it is not clear which cadaveric kidneys will be available, when they will be available, etc. Therefore while occupied houses and vacant houses are simultaneously allocated under the YRMH-IGYT mechanism, this is not possible in the context of kidney exchange. Instead, patients with live donors who are not themselves allocated a live donor kidney will be assigned to the cadaver queue (with a priority reflecting whether their donor's kidney was donated to someone on the queue).

Let $K$ denote the set of living donor kidneys at a particular time. While patients and their doctors may define their preferences over kidneys as they wish, here we consider, for specificity, 
the preferences that come from maximizing the probability of a successful transplant. Given any patient, part of $K$ is outside the feasible set due to ABO blood-type incompatibility or a positive crossmatch. Among feasible kidneys, HLA match (Opelz [1997]), donor age, kidney size, etc. play a significant role in the graft survival. Therefore patients have heterogenous preferences over compatible kidneys. In what follows we will consider all preferences to be strict. If only direct exchanges among donor-recipient pairs are considered, one can directly use Gale's Top Trading Cycles mechanism. However this will not allow for indirect exchanges. We will need to modify the model and the mechanism to allow for this possibility. Since the supply of specific cadaveric donor kidneys is not predictable, a patient who wishes to trade his donor's kidney in return for a priority in the cadaveric kidney waiting list is receiving a lottery. Taking this into consideration the patient, doctor, and donor can decide whether this option is acceptable and if so, where it ranks in the patient's preferences.

Given a patient $t_{i}$, let $K_{i} \subset K$ denote the set of living donor kidneys that are compatible with patient $t_{i}$. Let $w$ denote the option of entering the waiting list with priority reflecting the donation of his donor's kidney $k_{i}$, and $P_{i}$ denote his strict preferences over $K_{i} \cup\left\{k_{i}, w\right\}$. For our purposes the relevant part of $P_{i}$ is the ranking up to kidney $k_{i}$ or $w$, whichever ranks higher. If patient $t_{i}$ ranks kidney $k_{i}$ at the top of his preferences that means he and his donor do not wish to participate in an exchange. If patient $t_{i}$ ranks $k_{i}$ on top of $w$ that means he and his donor do not consider exchanging kidney $k_{i}$ with a priority in the cadaveric kidney waiting list.

We can now formalize a (static) kidney exchange problem consisting of a set of donorrecipient pairs $\left\{\left(k_{1}, t_{1}\right), \ldots,\left(k_{n}, t_{n}\right)\right\}$, a set of compatible kidneys $K_{i} \subset K=\left\{k_{1}, \ldots, k_{n}\right\}$ for

each patient $t_{i}$, and a strict preference relation $P_{i}$ over $K_{i} \cup\left\{k_{i}, w\right\}$ for each patient $t_{i}$. The outcome of a kidney exchange problem is a matching of kidneys/waitlist option to patients such that each patient $t_{i}$ is either assigned a kidney in $K_{i} \cup\left\{k_{i}\right\}$ or the waitlist option $w$, and no kidney can be assigned to more than one patient although the waitlist option $w$ can be assigned to several patients. A kidney exchange mechanism selects a matching for each kidney exchange problem. We are almost ready to introduce the Top Trading Cycles and Chains (TTCC) mechanism, a generalization of the TTC mechanism, for kidney exchange. First we give a few definitions and observations to facilitate the description of the mechanism.

\subsection{Cycles and w-Chains}

The mechanism relies on an algorithm consisting of several rounds. In each round each patient $t_{i}$ points either towards a kidney in $K_{i} \cup\left\{k_{i}\right\}$ or towards $w$, and each kidney $k_{i}$ points to its paired recipient $t_{i}$.

A cycle is an ordered list of kidneys and patients $\left(k_{1}^{\prime}, t_{1}^{\prime}, k_{2}^{\prime}, t_{2}^{\prime}, \ldots, k_{m}^{\prime}, t_{m}^{\prime}\right)$ such that kidney $k_{1}^{\prime}$ points to patient $t_{1}^{\prime}$, patient $t_{1}^{\prime}$ points to kidney $k_{2}^{\prime}, \ldots$, kidney $k_{m}^{\prime}$ points to patient $t_{m}^{\prime}$, and patient $t_{m}^{\prime}$ points to kidney $k_{1}^{\prime}$. Cycles larger than a single pair are associated with direct 
exchanges, very much like the paired-kidney-exchange programs, but may involve more than two pairs, so that patient $t_{1}^{\prime}$ is assigned kidney $k_{2}^{\prime}$, patient $t_{2}^{\prime}$ is assigned kidney $k_{3}^{\prime}, \ldots$, patient $t_{m}^{\prime}$ is assigned kidney $k_{1}^{\prime}$. Note that each kidney or patient can be part of at most one cycle and thus no two cycles intersect.

A $w$-chain is an ordered list of kidneys and patients $\left(k_{1}^{\prime}, t_{1}^{\prime}, k_{2}^{\prime}, t_{2}^{\prime}, \ldots, k_{m}^{\prime}, t_{m}^{\prime}\right)$ such that kidney $k_{1}^{\prime}$ points to patient $t_{1}^{\prime}$, patient $t_{1}^{\prime}$ points to kidney $k_{2}^{\prime}, \ldots$, kidney $k_{m}^{\prime}$ points to patient $t_{m}^{\prime}$, and patient $t_{m}^{\prime}$ points to $w$. We refer to the pair $\left(k_{m}^{\prime}, t_{m}^{\prime}\right)$ whose patient receives a cadaver kidney in a w-chain as the head and the pair $\left(k_{1}^{\prime}, t_{1}^{\prime}\right)$ whose donor donates to someone on the cadaver queue as the tail of the w-chain. W-chains are associated with indirect exchanges but unlike in a cycle, a kidney or a patient can be part of several w-chains. One practical possibility is choosing among w-chains with a well-defined chain selection rule, very much like the rules that establish priorities on the cadaveric waiting list. The current pilot indirect exchange programs in the U.S. choose the minimal w-chains, consisting of a single donor-recipient pair, but this may not be efficient. Selection of longer w-chains will benefit other patients as well and therefore the choice of a chain selection rule has efficiency implications (see Theorem 1). Chain selection rules may be also used for specific policy objectives such as increasing the inflow of type $\mathrm{O}$ living donor kidneys to the cadaveric waiting list. Whenever $\mathrm{w}$-chain $\left(k_{1}^{\prime}, t_{1}^{\prime}, \ldots, k_{m}^{\prime}, t_{m}^{\prime}\right)$ is selected in the algorithm, patient $t_{1}^{\prime}$ is assigned kidney $k_{2}^{\prime}$, patient $t_{2}^{\prime}$ is assigned kidney $k_{3}^{\prime}, \ldots$, patient $t_{m-1}^{\prime}$ is assigned kidney $k_{m}^{\prime}$, patient $t_{m}^{\prime}$ receives high priority for the next compatible kidney in the cadaveric waiting list, and kidney $k_{1}^{\prime}$ is either offered to the cadaveric waiting list or to another patient with a paired donor.

Lemma 1 Consider a graph in which both the patient and the kidney of each pair are distinct nodes as is the waitlist option w. Suppose each patient points either towards a kidney or w, and each kidney points to its paired recipient. Then either there exists a cycle or each pair is the tail of some w-chain.

We can now introduce the TTCC mechanism. Because the exchange mechanism interacts with many parts of the kidney transplant environment, it will clarify the discussion to start by indicating which parts of the environment we take as fixed for our present purpose. First, we take the operation of the cadaver queue as fixed. The cadaver queue can be thought of as a stochastic arrival process of cadavers and patients, interacting with a scoring rule that determines which patients are offered which cadaver kidneys. We also take as fixed how patients whose donors donate a kidney to someone on the queue are given high priority on the queue, e.g. by being given points in the scoring rule. ${ }^{4}$ We also take as given the size of the live kidney

\footnotetext{
${ }^{4}$ Depending on how this priority is given, patients may need to be aware of the current population of the queue to evaluate the desirability of the w option. Liran Einav and Muriel Niederle have shared with us interesting ideas about how to further model the desirability of the w option dynamically, taking into account that others may enter the queue with high priority, but we will not pursue this here.
} 
exchange, i.e. the set of patient-donor pairs is taken to be fixed. In practice, the set of patientdonor pairs will grow as the geographic area served by the kidney exchange is increased, or as the time between exchanges is increased. A larger pool of possible exchanges will increase the potential efficiency gains that can be realized by exchange, but will also increase the size of the trading cycles/w-chains that might be needed to achieve these efficiencies. We will keep track of both of these when we report simulations. Both the operation of the cadaver queue, and the frequency and scope of the kidney exchange will influence patients' "reservation utility," i.e. how they compare various opportunities for direct or indirect exchange to the option of not making any exchange now, but waiting for a future opportunity. Patients can express this reservation utility by where they rank their own donor in their preferences.

\subsection{The Exchange Mechanism}

For the mechanism defined below, we assume that when one among multiple w-chains must be selected, a fixed chain selection rule is invoked. We will consider a number of such rules, and their implications for incentives, efficiency, and equity.

Throughout the procedure kidneys are assigned to patients through a series of exchanges. Some patients and their assigned kidneys will be immediately removed from the procedure, while others will remain with their assignments but they will assume a passive role. So at any point in the procedure, some agents may no longer be participants, some participants will be active, and the others passive.

For a given kidney exchange problem, the TTCC mechanism determines the exchanges as follows:

1. Initially all kidneys are available and all agents are active. At each stage of the procedure each remaining active patient $t_{i}$ points to his most preferred remaining unassigned kidney or to the waitlist option $w$, whichever is more preferred, each remaining passive patient continues to point to his assignment, and each remaining kidney $k_{i}$ points to its paired recipient $t_{i}$.

2. By Lemma 1, there is either a cycle, or a w-chain, or both.

(a) Proceed to Step 3 if there are no cycles. Otherwise locate each cycle and carry out the corresponding exchange (i.e. each patient in the cycle is assigned the kidney he is pointing to). Remove all patients in a cycle together with their assignments.

(b) Each remaining patient points to his top choice among remaining kidneys and each kidney points to its paired recipient. Locate all cycles, carry out the corresponding exchanges, and remove them. Repeat until no cycle exists.

3. If there are no pairs left, we are done. Otherwise by Lemma 1, each remaining pair is the tail of a w-chain. Select only one of the chains with the chain selection rule. The 
assignment is final for the patients in the selected w-chain. The chain selection rule also determines whether the selected w-chain is removed and the associated exchanges are all immediately assigned (including the kidney at the tail, which is designated to go to a patient on the cadaver queue), or if the selected w-chain is kept in the procedure although each patient in it is passive henceforth. ${ }^{5}$

4. After a w-chain is selected, new cycles may form. Repeat Steps 2 and 3 with the remaining active patients and unassigned kidneys until no patient is left.

At the end of the procedure, each patient with a living donor is assigned a kidney (or a high priority place on the waiting list). However that does not necessarily mean each of these patients receives a transplant. In particular a minimal cycle $\left(k_{i}, t_{i}\right)$ consisting of a single patient-donor pair may be a pair that was not offered a sufficiently desirable kidney in the current exchange, and chooses to wait in the hope of exchanging for a high quality living donor kidney the next time the exchange is run, after new donors have entered the system.

Example 1: Consider a kidney exchange problem with 12 pairs $\left(k_{1}, t_{1}\right), \ldots,\left(k_{12}, t_{12}\right)$ with preferences as follows:

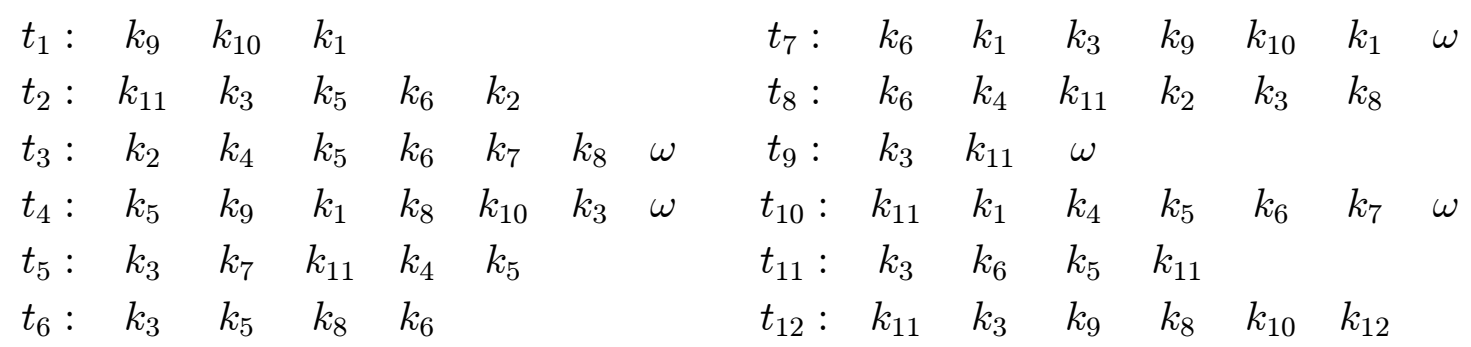

Suppose that patients are ordered in a priority-list based on their indices starting with the patient with the smallest index. We use the following chain selection rule: Choose the longest $\mathrm{w}$-chain. In case the longest w-chain is not unique, choose the w-chain with the highest priority patient; if the highest priority patient is part of more than one, choose the w-chain with the second highest priority patient, and so on. Keep the selected w-chains until the termination.

The execution of the TTCC mechanism is given in the following five figures:

[Figures 1-5 about here]

The final matching is $\left(\begin{array}{cccccccccccc}t_{1} & t_{2} & t_{3} & t_{4} & t_{5} & t_{6} & t_{7} & t_{8} & t_{9} & t_{10} & t_{11} & t_{12} \\ k_{9} & k_{11} & k_{2} & k_{8} & k_{7} & k_{5} & k_{6} & k_{4} & \omega & k_{1} & k_{3} & k_{10}\end{array}\right)$.

\footnotetext{
${ }^{5}$ The relevance of the last point is the following: Whenever a w-chain $\left(k_{1}^{\prime}, t_{1}^{\prime}, \ldots, k_{m}^{\prime}, t_{m}^{\prime}\right)$ is selected, even though the assignments of all patients in the w-chain are finalized, the kidney $k_{1}^{\prime}$ at the tail of the w-chain can be utilized in two possible ways: It can immediately be offered to the waiting list (in which case the w-chain is removed) or it may be made available to the remaining patients as the process continues and hence the selected w-chain may possibly grow later on, although the patients already in it are not affected.
} 
It is worth emphasizing that the chain selection policy does not affect a patient who is at the head of a chain: Since he points to the waitlist option, he will eventually be selected regardless of the chain selection rule. However whether his intended donor's kidney is offered to the cadaveric waiting list or another patient with a living donor depends on the rule. Depending on policy priorities, one may consider adopting a number of alternative chain selection rules. For example:

a. Choose minimal w-chains and remove them.

b. (c.) Choose the longest w-chain and remove it (keep it). If the longest w-chain is not unique then use a tie-breaker to choose among them.

d. (e.) Prioritize patient-donor pairs in a single list. Choose the w-chain starting with the highest priority pair and remove it (keep it).

A w-chain that is formed at an interim step of the procedure may grow at subsequent steps unless it is removed; hence the immediate removal of w-chains has a potential efficiency cost. Therefore the following "hybrid" of chain selection rules d. and e. may appeal to those who wish to moderate the efficiency loss while increasing the inflow of type $O$ living kidneys to the cadaveric waiting list.

f. Prioritize the patient-donor pairs so that pairs with type $\mathrm{O}$ donor have higher priorities than those who do not. Choose the w-chain starting with the highest priority pair; remove it in case the pair has a type $\mathrm{O}$ donor but keep it otherwise.

\subsection{Efficiency and Incentives}

In what follows, we will speak of Pareto efficiency in terms of the agents in the kidney exchange problem, namely the paired patients and donors who are available to participate in the kidney exchange. Given a kidney exchange problem, a matching is Pareto efficient if there is no other matching which is weakly preferred by all patients and donors and strictly preferred by at least one patient-donor pair. A kidney exchange mechanism is efficient if it always selects a Pareto efficient matching among the participants present at any given time.

Theorem 1 Consider a chain selection rule such that any w-chain selected at a non-terminal round remains in the procedure and thus the kidney at its tail remains available for the next round. The TTCC mechanism, implemented with any such chain selection rule, is efficient.

Chain selection rules that remove a selected w-chain before termination of the algorithm, on the contrary, may yield Pareto inefficient outcomes.

Roth [1982] showed for the housing model that truthful preference revelation is a dominant strategy of the preference revelation game induced by the TTC mechanism, and hence an agent 
can never profit by misrepresenting his preferences. Recall that, in the absence of indirect exchanges, the static kidney exchange problem is a housing market, and therefore the Roth [1982] result immediately applies. ${ }^{6}$ When indirect exchanges are allowed, whether the TTCC mechanism is strategy-proof depends on the choice of the chain selection rule.

Theorem 2 Consider the chain selection rules a, $d$, e, and f. The TTCC mechanism, implemented with any of these chain selection rules, is strategy-proof.

Among these four chain selection rules, the last two are especially appealing: Rule e yields an efficient and strategy-proof mechanism, whereas Rule $\mathrm{f}$ gives up efficiency in order to increase the inflow of type $\mathrm{O}$ kidneys to the cadaveric waiting list. On the negative side, strategyproofness of TTCC is lost if one adopts a chain selection rule that chooses among the longest w-chains.

Example 2: Consider the problem in Example 1, but suppose patient $t_{4}$ misrepresents his preferences as $P_{4}^{\prime}=k_{5}, k_{1}, k_{9}, \ldots$ improving the ranking of kidney $k_{1}$. While Round 1 and Round 2 remain as in Example 1, Round 3 changes and this time the longest w-chain at Round 3 is $W_{4}=\left(k_{8}, t_{8}, k_{4}, t_{4}, k_{1}, t_{1}, k_{9}, t_{9}\right)$. Therefore patient $t_{4}$ is assigned kidney $k_{1}$ instead of kidney $k_{8}$, making his preference misrepresentation profitable.

\section{Simulations}

The theoretical treatment of the TTCC mechanism makes clear that larger exchanges may yield welfare gains, but it gives no idea of their magnitude. The following simulations are meant as a first step in that direction, and as a "proof of concept" to demonstrate that the gains are potentially substantial. We use data where it exists, e.g. on the likelihood of mismatches and positive crossmatches (see Table 2). Where no data exist-on the willingness of patients and donors to trade a live donation for priority on the cadaver queue-we do robustness checks by simulating a wide range of preferences.

Patient and Donor Characteristics: In addition to characteristics reported in Table 2, for the HLA characteristics of the population, we use the distribution reported in Zenios [1996] using the UNOS registration data for years between 1987 and 1991. We assume that all HLA proteins and blood-type are independently distributed following Zenios [1996]. For simplicity, we consider unrelated donor-patient pairs. About 25.3\% all living-donor transplants were in

\footnotetext{
${ }^{6}$ That is, at any specific time, a patient cannot receive a more preferred kidney by misrepresenting his preferences, which include his option value for the possibility that his donor's kidney can be used in a future exchange. We emphasize that of course we speak of strategy proofness in the limited strategy space, the space of stated preferences, we have modeled for the kidney exchange problem. There may remain strategic issues associated with other aspects of the organ transplant process, such as being registered at multiple transplant centers and hence appearing on multiple regional waiting lists.
} 
this category in 2001. We use UNOS data to find the conditional distribution of the age of a non-spousal unrelated donor given that he is an adult. We assume that HLA and blood-type characteristics of the donor have the same distribution as the patients', the characteristics of a non-spousal unrelated donor are independently distributed with the patient, and the characteristics of a spouse are independently distributed with the patient except his or her age. We assume that the spouse age is the same as the patient age.

Preference Construction: The preferences of patients are determined using the survival analysis of grafts reported in Mandal et al. [2003]. This analysis uses data obtained from first-time kidney-only transplants between 1995 and 1998 in the United States Renal Data System (USRDS) database. We assume that the utility function of each patient depends on the number of HLA mismatches $(x)$ and the donor age $(y)$. In the "rational" preference construction, following Mandal et al. [2003], we assume that each patient younger than 60 has a utility function $u(x, y)=-0.514 x-\frac{y}{10}$, and each patient 60 and older has a utility function $u(x, y)=-0.510 x-\frac{y}{10}$. We also consider a "cautious" preference construction. Under cautious preferences, we assume that patient $t_{i}$ prefers donor $k_{j} \in K_{i}$ to his own donor $k_{i}$ only if kidney $k_{i}$ is not compatible with him, or if although kidney $k_{i}$ is compatible with him, it has more than an equivalent of one additional HLA mismatch than kidney $k_{j}$ has.

Under both preference scenarios, the waitlist option may or may not be considered acceptable by a patient. Since the expected quality of HLA match is very low when a patient is given priority in the waiting list and since the graft failure rates are significantly higher for cadaveric kidneys than living-donor kidneys, we assume that a patient considers the waitlist option acceptable only if his donor is not compatible with him. We also assume that the patients who consider this option acceptable prefer any compatible living-donor kidney to this option. Because there is no reliable data available on the rate of patients who consider this option acceptable and because it depends on how priority is given, we consider two treatments, in which $0 \%$ and $40 \%$ of the patients with incompatible donors prefer the waitlist option to their own donors.

Simulated Mechanisms: We consider four exchange mechanisms to contrast with the noexchange regime: (1) Paired-kidney-exchange mechanism, (2) TTC mechanism, (3) paired and indirect exchange mechanism, and (4) TTCC mechanism with the efficient and strategy-proof chain selection rule e. In our simulations, we randomly simulate a sample of $n$ donor-patient pairs using the population characteristics explained above. Then, we determine the preferences of patients over kidneys in the sample: For each patient $t_{i}$, we first check whether a donor $k_{j}$ is ABO-compatible. If $k_{j}$ is ABO-compatible, then we check whether there is a positive crossmatch between $t_{i}$ and $k_{j}$. If they test negative for crossmatch, then $k_{j}$ is in the compatible donor set $K_{i}$ of patient $t_{i}$. After finding the set of compatible kidneys for each patient, we obtain a preference ordering on this set, using the utility functions described above. We construct 4 sets of preferences for each patient using the rational or cautious preference construction and assuming that $0 \%$ or $40 \%$ of patients with incompatible donors consider the waitlist option 
acceptable. We simulate each of the five mechanisms under these four preference scenarios. We use a Monte-Carlo simulation size of 100 trials for three different population sizes of 30, 100, and 300 pairs.

Discussion of Results: The simulation results suggest that substantial gains in the number and match quality of transplanted kidneys might result from adoption of the TTCC mechanism. We report the details of this analysis in 3 tables. The rows of the tables refer to different regimes, under different preference constructions, and different population sizes.

Table 3 reports the general patient statistics under each regime. The first column reports the total live donor transplants as percentage of the population size, which is the sum of next two columns, transplants from own compatible donor and transplants from trades. The forth column is the percentage of patients upgraded to the top of the waitlist through indirect exchanges. The fifth column reports the quality of matches in the live donor transplants: The lower the HLA mismatch is, the higher the odds of graft survival. Standard errors are reported below the estimates.

In Table 4, we report the effect of each regime on the waitlist additions for each blood type. The columns are separated into two main groups. The first group reports the net percentage of patients sent to the top of the waitlist due to indirect exchanges (the percentages are taken with respect to all paired patients). This is a net upgrade burden, i.e. the difference between the patients added at the top of the list and the living-donor kidneys made available for the waitlist patients. The second group reports (again as a percentage of all paired patients) the rate of paired patients who nonetheless are sent to the cadaveric waiting list because the patient is not assigned a living-donor kidney.

In Table 5, we report the sizes of cycles and w-chains under each mechanism. The columns are divided into two groups for cycles and w-chains. Each group reports the number, the average length, the average maximum (per group, over all 100 trials) length of cycles/w-chains and the length of the longest cycle/w-chain encountered in all 100 trials. The lengths of cycles/w-chains are measured in pairs. Standard errors are reported below the estimates.

Next we highlight a number of these results:

1. A transition to the TTCC mechanism will significantly improve the utilization rate of potential unrelated living-donor kidneys: Assuming a population size of 100 pairs, while approximately $55 \%$ of potential living-donor kidneys are utilized under the no-exchange regime, this rate increases to $73.5 \%$ under the paired-kidney-exchange, and to $88-89.5 \%$ under the TTCC mechanism. The efficiency gain gets larger as the population size grows further.

2. A transition to TTCC significantly decreases the HLA mismatch, especially for the large populations.

3. Under the TTCC mechanism, average/maximal sizes of cycles/w-chains increase as the population grows although the increase is less than proportional. 
4. Type O patients without living donors benefit from the TTCC mechanism. The TTCC mechanism significantly reduces the incidence of type $\mathrm{O}$ patients with potential donors who are forced to rely on the cadaveric waiting list because of an incompatibility. Consider a population size of 100 donor-recipient pairs (with the distribution of blood types, etc. of the UNOS dataset). When no exchange is allowed, on average 27.6 type $\mathrm{O}$ patients who have a willing donor nevertheless join the waiting list for a cadaver kidney because they are incompatible (by blood type or positive crossmatch) with their donor. This rate reduces to 21.9 under the paired-kidney-exchange and further to 5.5-5.7 under the TTCC mechanism. That means out of 100 patients with living donors, 16.2-16.4 patients with O blood types drop out of competition for cadaver kidneys as a result of a change from paired-kidney-exchange to the TTCC mechanism. The corresponding cost of this change to type $\mathrm{O}$ patients with no living donors is that only 3.5-4.2 type $\mathrm{O}$ patients with living donors are moved to the head of the cadaver queue. ${ }^{7}$ So the reduction in demand for $\mathrm{O}$ type cadaver kidneys is much larger than the number of patients who are inserted at the head of the queue. ${ }^{8}$

More detail on the simulations can be found in Roth, Sönmez \& Ünver [2003].

\section{Conclusion}

The TTCC mechanism is motivated by the present small scale pilot paired and indirect kidney exchange programs. We have concentrated here on its advantages over the simplest kinds of exchange. But, as we begin to talk with members of the transplantation community about first steps towards implementing such exchanges, it is clear that there are obstacles to be overcome. Some are the same obstacles that have kept existing exchange programs very small. Among these are the absence of registries of incompatible or poorly matched patient-donor pairs. ${ }^{9}$ Also,

\footnotetext{
${ }^{7}$ This benefit/cost rate is significantly better than the benefit/cost rate that results from a change from paired-kidney-exchange to paired/indirect-kidney-exchange because, in an indirect exchange, only occasionally will a type $\mathrm{O}$ living donor kidney be sent to the waiting list to compensate for the type $\mathrm{O}$ patient who receives priority on the queue. In our simulations with 100 paired patients, a transition from paired-kidney-exchange to paired/indirect-kidney-exchange drops $21.89-13.42=8.47$ patients from the waiting list at a cost of moving 8.25 paired patients to the head of the cadaver queue.

${ }^{8} \mathrm{We}$ emphasize that the welfare implications of this for type $\mathrm{O}$ patients on the cadaver queue is much clearer when we think of patients who enter the queue after kidney exchange is already well established. There can still be important welfare concerns about individual patients during the transition to an indirect exchange regime, since an $\mathrm{O}$ type patient who has already been on the waiting list for three years receives relatively less benefit from the reduction in new $\mathrm{O}$ type patients joining the list than does a new patient, but suffers increased waiting time when an $\mathrm{O}$ type patient is given higher priority on the queue. What the simulations suggest is that, once a kidney exchange regime is up and running, type $\mathrm{O}$ patients without a living donor who enter the queue for a cadaver kidney will be helped, not harmed, by the fact that exchanges are being made.

${ }^{9}$ Such a registry would need to include tissue typing data, and present medical privacy laws mean that this will be difficult to collect ex-post. We have begun exploratory discussions with our medical colleagues
} 
exchanges require coordination of multiple operating rooms and surgical teams, two for each patient-donor pair, so larger exchanges will require more coordination.

As a registry starts to be assembled, it may be that the main initial advantage will simply be to allow paired exchanges to be conducted more often. However as the registry grows larger, and the practical difficulties are overcome, we have seen that there will be additional benefits to be reaped from more flexible forms of exchange that enlarge the set of possible exchanges. Compared to simple paired and indirect exchanges, the wider exchange implemented by the TTCC mechanism creates additional welfare gains in several ways. First, allowing longer cycles of exchange will allow some transplantations that could not be arranged with pairwise exchanges, and it will increase the scope for improving the quality of the resulting matches. And by allowing more live donations, it will reduce the competition for cadaver kidneys. Second, longer chains for combined indirect and paired exchange will allow an indirect exchange to benefit more than one patient-donor pair, and by doing so will also increase the number of live donations. And third, by increasing the number of $\mathrm{O}$ type patients who can receive live donations, and by managing the flow of kidneys and patients to the cadaver queue, this can be done in ways that help $\mathrm{O}$ type patients who have no live donor. ${ }^{10}$

In summary, the design of practical exchange mechanisms is the "engineering" part of economic theory, and must deal with constraints omitted from more abstract endeavors. The organization of a kidney exchange faces some of the most stringent constraints we have encountered, arising from social/legal/ethical concerns, as well as from the practical requirements of kidney transplantation and patient care. In the future, some of those constraints may be relaxed, e.g. through advances in dealing with immunological incompatibilities, or in using xenotransplants (animal organs) to relieve the organ shortage, or through some other way of radically increasing organ availability. In the meantime, increasing kidney exchange among willing donor-recipient pairs offers a way to benefit those pairs who are not well matched, and, by increasing live organ donation and reducing competition for cadaver organs, also benefiting patients who do not have live donors. This benefit is sufficiently widespread that it helps even the most vulnerable patients, the type $\mathrm{O}$ patients without a live donor.

in New England about the possibility of developing a program to identify incompatible and poorly matched patient-donor pairs, and collect tissue typing data from potential donors.

${ }^{10}$ To eliminate or reduce the adverse affect of indirect exchange programs on patients with no living donors, Zenios, Woodle \& Ross [2001] propose preferential selection of O blood-type paired donors for patients with multiple potential donors who wish to participate in indirect exchange programs. Their proposal is consistent with a direct extension of the TTCC mechanism to a model with multiple potential donors when the flexibility on chain selection is used to increase the inflow of O blood-type kidneys to the cadaveric waiting list. See Roth, Sönmez and Ünver [2003] for more on exchange when patients may have multiple potential donors. 


\section{A Appendix: Proofs}

Proof of Lemma 1: Consider a graph where each patient points either towards a kidney or $w$, and each kidney points to its paired recipient. Suppose there is no cycle. Consider an arbitrary pair $\left(k_{i}, t_{i}\right)$. Start with kidney $k_{i}$ and follow the path in the graph. Since there are no cycles, no kidney or patient can be encountered twice. Hence by the finiteness of pairs, the path shall terminate at $w$. This is the w-chain initiated by pair $\left(k_{i}, t_{i}\right)$ completing the proof. $\diamond$

Proof of Theorem 1: Let the TTCC mechanism be implemented with a chain selection rule such that any w-chain selected at a non-terminal round remains in the procedure and the kidney at its tail remains available for the next round. Any patient whose assignment is finalized in Round 1 has received his top choice and cannot be made better off. Any patient whose assignment is finalized in Round 2 has received his top choice among the kidneys not already assigned as part of an exchange (since chains are not removed, so the kidney at their tail remains available), and cannot be made better off without hurting a patient whose assignment was finalized in Round 1. Proceeding in a similar way, no patient can be made better off without hurting a patient whose assignment is finalized in an earlier round. Therefore TTCC mechanism selects a Pareto efficient matching at any given time provided that w-chains are removed at the termination.

We will prove Theorem 2 for the chain selection rule a and for a class of "priority chain selection rules" that covers rules d, e, and f. Under this class each ordering of patient-donor pairs together with a fixed pair defines a chain selection rule, and it is given as follows: Order donor-patient pairs in a single priority list. Fix a pair $\left(k_{j}, t_{j}\right)$. Whenever a w-chain is to be selected, select the w-chain starting with the highest priority pair $\left(k_{i}, t_{i}\right)$, and remove the wchain if the pair $\left(k_{i}, t_{i}\right)$ has strictly higher priority than the fixed pair $\left(k_{j}, t_{j}\right)$ and keep it until termination otherwise.

First, we prove the following lemma which will be useful for the proof of Theorem 2 .

Lemma 2 Consider the TTCC mechanism implemented with a priority based chain selection rule. Fix the stated preferences of all patients except patient $t_{i}$ at $P_{-i}$. Suppose that in the algorithm the assignment of patient $t_{i}$ is finalized at Round $s$ under $P_{i}$ and at Round $s^{\prime}$ under $P_{i}^{\prime}$. Suppose $s \leq s^{\prime}$. Then the remaining active patients and unassigned kidneys at the beginning of Round s are the same, whether patient $t_{i}$ announces $P_{i}$ or $P_{i}^{\prime}$.

Proof of Lemma 2: Patient $t_{i}$ fails to participate in a cycle or a selected w-chain prior to Round $s$ under either preferences. Therefore at any round prior to Round $s$ not only the highest priority active patient is the same, whether patient $t_{i}$ announces $P_{i}$ or $P_{i}^{\prime}$, but also the same cycles/w-chains form, and in case there are no cycles, the same w-chain is selected, whether patient $t_{i}$ announces $P_{i}$ or $P_{i}^{\prime}$. Hence the remaining active patients and unassigned kidneys at the beginning of Round $s$ are the same, whether patient $t_{i}$ announces $P_{i}$ or $P_{i}^{\prime}$. 
Proof of Theorem 2: We first consider the chain selection rule a. Recall that for each patient $t_{i}$, the relevant part of preference $P_{i}$ is the ranking up to $k_{i}$ or $w$, whichever is more preferred. Given the preference profile $\left(P_{i}\right)_{i=1}^{n}$, construct a new preference profile $\left(P_{i}^{\prime}\right)_{i=1}^{n}$ as follows: For each patient $t_{i}$ with $k_{i} P_{i} w$, let $P_{i}^{\prime}=P_{i}$. For each patient $t_{i}$ with $w P_{i} k_{i}$, construct $P_{i}^{\prime}$ from $P_{i}$ by swapping the ranking of $k_{i}$ and $w$. Note that $k_{i} P_{i}^{\prime} w$ for each patient $t_{i}$ and because the relevant part of preferences are the more preferred of $k_{i}$ and $w,\left\langle\left\{\left(k_{i}, t_{i}\right)\right\}_{i=1}^{n},\left(P_{i}^{\prime}\right)_{i=1}^{n}\right\rangle$, is a housing market. Let $\mu$ denote the outcome of the TTC mechanism for this housing market and construct matching $\nu$ from matching $\mu$ as follows: If $P_{i}^{\prime} \neq P_{i}$ and $\mu\left(t_{i}\right)=k_{i}$ then $\nu\left(t_{i}\right)=w$, otherwise $\nu\left(t_{i}\right)=\mu\left(t_{i}\right)$. The key observation is that $\nu$ is the outcome of the TTCC mechanism when it is implemented with the minimal w-chain selecting chain selection rule. Therefore by Roth [1982], a patient can never receive a more preferred kidney by a preference misrepresentation. He can receive the waitlist option $w$ by a misrepresentation but cannot profit from it. That is because the TTCC mechanism never assigns a patient a kidney that is inferior to $w$. Hence TTCC is strategy-proof with this choice of chain selection rule.

Next consider any of the priority based chain selection rules. Consider a patient $t_{i}$ with true preferences $P_{i}$. Fix an announced preference profile $P_{-i}$ for all other patients. We want to show that revealing his true preferences $P_{i}$ is at least as good as announcing any other preferences $P_{i}^{\prime}$ under the TTCC mechanism. Let $s$ and $s^{\prime}$ be the rounds at which patient $t_{i}$ leaves the algorithm under $P_{i}$ and $P_{i}^{\prime}$ respectively. We have two cases to consider.

Case 1: $s<s^{\prime}$. By Lemma 2, the same kidneys remain in the algorithm at the beginning of Round $s$ whether patient $t_{i}$ announces $P_{i}$ or $P_{i}^{\prime}$. Moreover, patient $t_{i}$ is assigned his top choice remaining at Round $s$ under $P_{i}$. Therefore his assignment under $P_{i}$ is at least as good as his assignment under $P_{i}^{\prime}$.

Case 2: $s \geq s^{\prime}$. After announcing $P_{i}^{\prime}$, the assignment of patient $t_{i}$ is finalized either by joining a cycle, or by joining a selected w-chain. We will consider the two cases separately.

Case 2a: The assignment of patient $t_{i}$ is finalized by joining a cycle under $P_{i}^{\prime}$.

Let $\left(k^{1}, t^{1}, k^{2}, \ldots, k^{r}, t_{i}\right)$ be the cycle patient $t_{i}$ joins, and thus $k^{1}$ be the kidney he is assigned under $P_{i}^{\prime}$. Next suppose he reveals his true preferences $P_{i}$. Consider Round $s^{\prime}$. By Lemma 2, the same active patients and available kidneys remain at the beginning of this round whether patient $t_{i}$ announces $P_{i}^{\prime}$ or $P_{i}$. Therefore at Round $s^{\prime}$, kidney $k^{1}$ points to patient $t^{1}$, patient $t^{1}$ points to kidney $k^{2}, \ldots$, kidney $k^{r}$ points to patient $t_{i}$. Moreover, they keep on doing so as long as patient $t_{i}$ remains. Since patient $t_{i}$ truthfully points to his best remaining choice at each round, he either receives a kidney better than kidney $k^{1}$ or eventually points to kidney $k^{1}$, completes the formation of cycle $\left(k^{1}, t^{1}, k^{2}, \ldots, k^{r}, t_{i}\right)$, and gets assigned kidney $k^{1}$.

Case 2b: The assignment of patient $t_{i}$ is finalized by joining a selected w-chain under $P_{i}^{\prime}$.

Let $\left(k^{1}, t^{1}, k^{2}, \ldots, k^{r}, t_{i}=t^{r}, k^{r+1}, \ldots, k^{r+m}, t^{r+m}\right)$ be the selected w-chain patient $t_{i}$ joins, where $r \geq 1$ and $m \geq 0$, under $P_{i}^{\prime}$. Therefore, under $P_{i}^{\prime}$, patient $t_{i}$ is assigned the kidney $k^{r+1}$ if $m \geq 1$ and the waitlist option $w$ if $m=0$. Also note that, given the considered class of priority based chain selection rules, pair $\left(k^{1}, t^{1}\right)$ is the highest priority pair in Round $s^{\prime}$. Next 
suppose patient $t_{i}$ reveals his true preferences $P_{i}$. Consider Round $s^{\prime}$. By Lemma 2, the same active patients and available kidneys remain at the beginning of this round whether patient $t_{i}$ announces $P_{i}^{\prime}$ or $P_{i}$. We will complete the proof by showing that, upon announcing his truthful preferences $P_{i}$, the assignment of patient $t_{i}$ is finalized in Round $s^{\prime}$ and thus he is assigned his top choice available at the beginning of Round $s^{\prime}$ : Recall that for this case there is no cycle in Round $s^{\prime}$ when patient $t_{i}$ announces $P_{i}^{\prime}$. Therefore when he announces his true preferences $P_{i}$, either there is no cycle in Round $s^{\prime}$ or there is one cycle that includes him. If it is the latter, then his assignment is finalized in Round $s^{\prime}$ and we are done. Otherwise, each pair initiates a w-chain by Lemma 1 and one of these w-chains has to be selected. By the choice of a priority based chain selection rule, this will be the w-chain that starts with the highest priority pair $\left(k^{1}, t^{1}\right)$. But the path starting with kidney $k^{1}$ passes through patient $t_{i}$ and therefore the selected w-chain includes patient $t_{i}$. Hence in this case as well his assignment is finalized in Round $s^{\prime}$ completing the proof.

\section{References}

[1] A. Abdulkadiroğlu \& T. Sönmez [1999] House allocation with existing tenants. Journal of Economic Theory 88, 233-260.

[2] M. Abecassis et. al [2002]. The Journal of the American Medical Association 284, 2919-2926.

[3] G. S. Becker \& J. J. Elias [2002] Introducing Incentives in the Market for Living Organ Donations. Working paper, University of Chicago.

[4] A. K. Mandal, J. J. Snyder, D. T. Gilbertson, A. J. Collins, \& J. R. Silkensen [2003] Does cadavaric donor renal transplantation ever provide better outcomes than live-donor renal transplantation? Transplantation 75, 494-500.

[5] P. Milgrom [forthcoming] Putting Auction Theory to Work, Cambridge University Press.

[6] E. W. Nelson, J. E. Childress, J. Perryman, V. Robards, A. Rowan, M. S. Seely, S. Sterioff, M. R. Swanson, [1993] Financial incentives for organ donation: A report of the payment subcommittee, United Network for Organ Sharing Ethics Committee.

[7] E. Olson [2003] A Tale of 6 Kidneys, or She Gave Him Her Love, He Gave Her His Kidney. New York Times Saturday, August 2, A7.

[8] G. Opelz [1997] Impact of HLA compatibility on survival of kidney transplants from unrelated live donors. Transplantation 64, 1473-1475.

[9] F. T. Rapaport [1986] The case for a living emotionally related international kidney donor exchange registry. Transplantation Proceedings 18, 5-9. 
[10] L. F. Ross, D. T. Rubin, M. Siegler, M. A. Josephson, J. R. Thistlethwaite, Jr., \& E S. Woodle [1997] Ethics of a paired-kidney-exchange program. The New England Journal of Medicine 336, 1752-1755.

[11] L. F. Ross \& E. S. Woodle [2000].Ethical issues in increasing living kidney donations by expanding kidney paired exchange programs. Transplantation 69, 1539-1543.

[12] A.E. Roth [1982] Incentive compatibility in a market with indivisibilities. Economics Letters $9,127-132$.

[13] A. E. Roth [2002] The Economist as Engineer: Game Theory, Experimentation, and Computation as Tools for Design Economics. Econometrica 70, 1341-1378.

[14] A. E. Roth \& E. Peranson [1999] The Redesign of the Matching Market for American Physicians: Some Engineering Aspects of Economic Design. American Economic Review $89,748-780$.

[15] A.E. Roth \& A. Postlewaite [1977] Weak versus strong domination in a market with indivisible goods. Journal of Mathematical Economics 4, 131-137.

[16] A.E. Roth, T. Sönmez, \& M.U. Ünver [2003] Kidney Exchange. NBER Working Paper No. w10002, September.

[17] R. M. Sade [2003] Assessing Initiatives to Increase Organ Donations, Prepared Witness Testimony, The House Committee on Energy and Commerce, W.J. "Billy" Tauzin, Chairman, Subcommittee on Oversight and Investigations, June 3.

[18] D. P. Scanlon, C. S. Hollenbeak, W. Lee, E. Loh, P. A. Ubel [2003] Does Competition for Transplantable Hearts Encourage Gaming of the Waiting List? Presented at the 8th Northeast Regional Health Economics Research Symposium, Boston University.

[19] L. Shapley \& H. Scarf [1974] On cores and indivisibility. Journal of Mathematical Economics 1, 23-28.

[20] S. Warmbir [2003] UIC hospital sued for Medicare fraud, Chicago Sun Times, July 29.

[21] S. Zenios [1996] Health care applications of optimal control theory. Ph.D. Thesis, MIT.

[22] S. Zenios, E. S. Woodle, \& L. F. Ross [2001] Primum non nocere: avoiding increased waiting times for individual racial and blood-type subsets of kidney wait list candidates in a living donor/cadaveric donor exchange program. Transplantation 66, 406-407. 
Table 1: US Kidney Transplants. The data for years 1992-2001 are constructed from the annual report of UNOS/OPTN, the data for 2002 are constructed from the national database of UNOS/OPTN. National database numbers are slightly higher than the annual report numbers due to continuous updating regarding previous years. Number of registrations may have multiple counts of patients since one patient may have registered in multiple centers for the waitlist.

\begin{tabular}{|c|c|c|c|c|c|}
\hline Year & $\begin{array}{c}\text { Cadaveric } \\
\text { Donors }\end{array}$ & $\begin{array}{c}\text { Cadaveric } \\
\text { Transplants }\end{array}$ & $\begin{array}{c}\text { Live } \\
\text { Donors }\end{array}$ & $\begin{array}{c}\text { All Waitlist } \\
\text { Patients }\end{array}$ & $\begin{array}{c}\text { New Waitlist } \\
\text { Additions }\end{array}$ \\
\hline \hline $\mathbf{1 9 9 2}$ & 4,276 & 7,202 & 2,535 & 22,063 & 15,224 \\
\hline $\mathbf{1 9 9 3}$ & 4,609 & 7,509 & 2,851 & 24,765 & 16,090 \\
\hline $\mathbf{1 9 9 4}$ & 4,797 & 7,638 & 3,009 & 27,258 & 16,538 \\
\hline $\mathbf{1 9 9 5}$ & 5,003 & 7,690 & 3,377 & 30,590 & 17,903 \\
\hline $\mathbf{1 9 9 6}$ & 5,038 & 7,726 & 3,649 & 34,000 & 18,328 \\
\hline $\mathbf{1 9 9 7}$ & 5,083 & 7,769 & 3,912 & 37,438 & 19,067 \\
\hline $\mathbf{1 9 9 8}$ & 5,339 & 8,017 & 4,361 & 40,931 & 20,191 \\
\hline $\mathbf{1 9 9 9}$ & 5,386 & 8,023 & 4,552 & 43,867 & 20,986 \\
\hline $\mathbf{2 0 0 0}$ & 5,490 & 8,089 & 5,324 & 47,596 & 22,269 \\
\hline $\mathbf{2 0 0 1}$ & 5,528 & 8,202 & 5,924 & 51,144 & 22,349 \\
\hline $\mathbf{2 0 0 2}$ & 5,630 & 8,534 & 6,233 & 54,844 & 23,494 \\
\hline
\end{tabular}


Table 2: American Caucasian patient and living donor characetristic distributions used in simulations. The frequencies are obtained from the UNOS data for various years. Patients are the new waitlist additions recorded between January 1995 and April 2003, except the gender data. The gender and living donor data were recorded between 1992 and 2001. Based on UNOS/OPTN data and annual report as of 7/14/2003 retrieved from http://www.optn.org. Positive crossmatch probability is reported by Zenios, Woodle \& Ross [2001].

\begin{tabular}{|c|c|}
\hline A. Patient ABO Blood Type & Frequency \\
\hline O & $45.6 \%$ \\
\hline A & $39.5 \%$ \\
\hline AB & $11.1 \%$ \\
\hline B. Patient Gender & $3.8 \%$ \\
\hline Female & Frequency \\
\hline Male & $40.9 \%$ \\
\hline \hline C. Patient Age & $59.1 \%$ \\
\hline$<18$ & Frequency \\
\hline $18-34$ & $5.6 \%$ \\
\hline $35-49$ & $13 \%$ \\
\hline $50-64$ & $34.9 \%$ \\
\hline$>64$ & $38.9 \%$ \\
\hline \hline D. Unrelated Living Donors & Frequency \\
\hline Spouse & $53.5 \%$ \\
\hline Other & $46.5 \%$ \\
\hline \hline E. Living Donor Age & Frequency \\
\hline$<18$ & $5.6 \%$ \\
\hline $18-34$ & $13 \%$ \\
\hline $35-49$ & $34.9 \%$ \\
\hline $50-64$ & $38.9 \%$ \\
\hline$>64$ & $7.6 \%$ \\
\hline F. Positive Crossmatch & Frequency \\
\hline Female Patient - Husband & $33.3 \%$ \\
\hline Other & $11.1 \%$ \\
\hline
\end{tabular}


Table 3: Number of Transplants and Quality of Match for $n=30, n=100$, and $n=300$

\begin{tabular}{|c|c|c|c|c|c|c|c|}
\hline $\begin{array}{l}\text { Pop. } \\
\text { Size }\end{array}$ & Pref. & $\begin{array}{c}\text { Exchange } \\
\text { Regime }\end{array}$ & $\begin{array}{c}\text { Total } \\
\text { Trans.\% } \\
\end{array}$ & $\begin{array}{c}\text { Own Donor } \\
\text { Trans.\% } \\
\end{array}$ & Trade\% & $\begin{array}{c}\text { Waitlist } \\
\text { Upgrade\% }\end{array}$ & $\begin{array}{l}\text { HLA } \\
\text { Mis. }\end{array}$ \\
\hline \multirow{9}{*}{$\mathbf{n}=\mathbf{3 0}$} & \multicolumn{7}{|l|}{ Waitlist $0 \%$} \\
\hline & All & None & $\begin{array}{l}54.83 \\
(8.96)\end{array}$ & $\begin{array}{l}54.83 \\
(8.96)\end{array}$ & $\begin{array}{c}0 \\
(0)\end{array}$ & $\begin{array}{c}0 \\
(0)\end{array}$ & $\begin{array}{c}4.79 \\
(0.25)\end{array}$ \\
\hline & All & Paired & $\begin{array}{l}68.50 \\
(9.90)\end{array}$ & $\begin{array}{l}54.83 \\
(8.96)\end{array}$ & $\begin{array}{l}13.67 \\
(9.40)\end{array}$ & $\begin{array}{c}0 \\
(0)\end{array}$ & $\begin{array}{c}4.78 \\
(0.24)\end{array}$ \\
\hline & Rational & TTC & $\begin{array}{c}82.47 \\
(10.14)\end{array}$ & $\begin{array}{l}23.03 \\
(9.44)\end{array}$ & $\begin{array}{c}59.43 \\
(13.57)\end{array}$ & $\begin{array}{c}0 \\
(0)\end{array}$ & $\begin{array}{c}4.16 \\
(0.22)\end{array}$ \\
\hline & Cautious & TTC & $\begin{array}{c}81.07 \\
(10.02)\end{array}$ & $\begin{array}{c}34.17 \\
(11.27)\end{array}$ & $\begin{array}{c}46.90 \\
(13.96)\end{array}$ & $\begin{array}{c}0 \\
(0)\end{array}$ & $\begin{array}{c}4.29 \\
(0.23)\end{array}$ \\
\hline & \multicolumn{7}{|l|}{ Waitlist $40 \%$} \\
\hline & All & Paired/Ind. & $\begin{array}{l}68.50 \\
(9.90)\end{array}$ & $\begin{array}{l}54.83 \\
(8.96)\end{array}$ & $\begin{array}{l}13.67 \\
(9.40)\end{array}$ & $\begin{array}{l}13.20 \\
(6.73)\end{array}$ & $\begin{array}{c}4.78 \\
(0.24)\end{array}$ \\
\hline & Rational & TTCC e & $\begin{array}{l}84.70 \\
(8.49\end{array}$ & $\begin{array}{l}21.23 \\
9.60)\end{array}$ & $\begin{array}{c}63.47 \\
(12.39)\end{array}$ & $\begin{array}{c}6.37 \\
(4.88)\end{array}$ & $\begin{array}{c}4.17 \\
(0.22)\end{array}$ \\
\hline & Cautious & TTCC e & $\begin{array}{l}83.57 \\
(8.53)\end{array}$ & $\begin{array}{c}32.93 \\
(10.98)\end{array}$ & $\begin{array}{c}50.63 \\
(12.54)\end{array}$ & $\begin{array}{c}6.13 \\
(4.39)\end{array}$ & $\begin{array}{c}4.29 \\
(0.22) \\
\end{array}$ \\
\hline \multirow{9}{*}{$n=100$} & \multicolumn{7}{|l|}{ Waitlist $0 \%$} \\
\hline & All & None & $\begin{array}{l}54.79 \\
(4.48)\end{array}$ & $\begin{array}{l}54.79 \\
(4.48)\end{array}$ & $\begin{array}{c}0 \\
(0)\end{array}$ & $\begin{array}{c}0 \\
(0)\end{array}$ & $\begin{array}{c}4.83 \\
(0.14)\end{array}$ \\
\hline & All & Paired & $\begin{array}{l}73.59 \\
(4.97)\end{array}$ & $\begin{array}{l}54.79 \\
(4.48)\end{array}$ & $\begin{array}{l}18.80 \\
(3.81)\end{array}$ & $\begin{array}{c}0 \\
(0)\end{array}$ & $\begin{array}{c}4.82 \\
(0.11)\end{array}$ \\
\hline & Rational & TTC & $\begin{array}{l}87.85 \\
(4.54)\end{array}$ & $\begin{array}{l}11.51 \\
(3.44)\end{array}$ & $\begin{array}{l}76.34 \\
(5.45)\end{array}$ & $\begin{array}{c}0 \\
(0)\end{array}$ & $\begin{array}{c}3.72 \\
(0.10)\end{array}$ \\
\hline & Cautious & TTC & $\begin{array}{l}87.23 \\
(4.73)\end{array}$ & $\begin{array}{l}24.01 \\
(4.48)\end{array}$ & $\begin{array}{l}63.22 \\
(5.46)\end{array}$ & $\begin{array}{c}0 \\
(0)\end{array}$ & $\begin{array}{c}3.86 \\
(0.11)\end{array}$ \\
\hline & \multicolumn{7}{|l|}{ Waitlist $40 \%$} \\
\hline & All & Paired/Ind. & $\begin{array}{l}73.59 \\
(4.97)\end{array}$ & $\begin{array}{l}54.79 \\
(4.48)\end{array}$ & $\begin{array}{l}18.80 \\
(3.81)\end{array}$ & $\begin{array}{l}10.24 \\
(3.07)\end{array}$ & $\begin{array}{c}4.82 \\
(0.11)\end{array}$ \\
\hline & Rational & TTCC e & $\begin{array}{l}89.44 \\
(3.85)\end{array}$ & $\begin{array}{l}10.29 \\
(3.26)\end{array}$ & $\begin{array}{l}79.15 \\
(4.40)\end{array}$ & $\begin{array}{c}3.96 \\
(1.97)\end{array}$ & $\begin{array}{c}3.71 \\
(0.10)\end{array}$ \\
\hline & Cautious & TTCC e & $\begin{array}{l}88.97 \\
(4.17)\end{array}$ & $\begin{array}{l}22.81 \\
(4.83)\end{array}$ & $\begin{array}{l}66.16 \\
(4.79)\end{array}$ & $\begin{array}{c}4.72 \\
(2.60)\end{array}$ & $\begin{array}{c}3.85 \\
(0.11)\end{array}$ \\
\hline & Waitlist $0 \%$ & & & & & & \\
\hline & All & None & $\begin{array}{l}53.92 \\
(2.82)\end{array}$ & $\begin{array}{l}53.92 \\
(2.82)\end{array}$ & $\begin{array}{c}0 \\
(0)\end{array}$ & $\begin{array}{c}0 \\
(0)\end{array}$ & $\begin{array}{c}4.81 \\
(0.08)\end{array}$ \\
\hline & All & Paired & $\begin{array}{l}75.03 \\
(2.72)\end{array}$ & $\begin{array}{l}53.92 \\
(2.82)\end{array}$ & $\begin{array}{l}21.11 \\
(2.51)\end{array}$ & $\begin{array}{c}0 \\
(0)\end{array}$ & $\begin{array}{c}4.81 \\
(0.07)\end{array}$ \\
\hline & Rational & TTC & $\begin{array}{l}91.05 \\
(3.35)\end{array}$ & $\begin{array}{c}5.72 \\
(1.28)\end{array}$ & $\begin{array}{l}85.32 \\
(3.61)\end{array}$ & $\begin{array}{c}0 \\
(0)\end{array}$ & $\begin{array}{c}3.29 \\
(0.06)\end{array}$ \\
\hline $\mathrm{n}=\mathbf{3 0 0}$ & Cautious & TTC & $\begin{array}{l}90.86 \\
(3.31)\end{array}$ & $\begin{array}{l}15.36 \\
(2.20)\end{array}$ & $\begin{array}{l}75.51 \\
(4.07)\end{array}$ & $\begin{array}{c}0 \\
(0)\end{array}$ & $\begin{array}{c}3.40 \\
(0.06)\end{array}$ \\
\hline & Waitlist $40 \%$ & & & & & & \\
\hline & All & Paired/Ind. & $\begin{array}{l}75.03 \\
(2.72)\end{array}$ & $\begin{array}{l}53.92 \\
(2.82)\end{array}$ & $\begin{array}{l}21.11 \\
(2.51)\end{array}$ & $\begin{array}{c}9.77 \\
(1.73)\end{array}$ & $\begin{array}{c}4.81 \\
(0.07)\end{array}$ \\
\hline & Rational & TTCC e & $\begin{array}{l}92.29 \\
(2.98)\end{array}$ & $\begin{array}{c}5.00 \\
(1.29)\end{array}$ & $\begin{array}{l}87.29 \\
(3.05)\end{array}$ & $\begin{array}{c}3.02 \\
(1.36)\end{array}$ & $\begin{array}{c}3.29 \\
(0.06)\end{array}$ \\
\hline & Cautious & TTCC e & $\begin{array}{l}92.17 \\
(2.93)\end{array}$ & $\begin{array}{l}14.42 \\
(2.10)\end{array}$ & $\begin{array}{l}77.75 \\
(3.26)\end{array}$ & $\begin{array}{c}3.19 \\
(1.40)\end{array}$ & $\begin{array}{c}3.39 \\
(0.06)\end{array}$ \\
\hline
\end{tabular}


Table 4: ABO Composition of Net Waitlist Upgrades and Other Waitlist Patients as Percentage of $n=30, n=100$, and $n=300$. Net Waitlist Upgrades is the difference between the number of upgraded patients of certain blood type and the number of live donor kidneys sent to the waitlist of the same blood type.

\begin{tabular}{|c|c|c|c|c|c|c|c|c|c|c|c|c|}
\hline \multirow{2}{*}{$\begin{array}{l}\text { Pop. } \\
\text { Size }\end{array}$} & \multirow[t]{2}{*}{ Pref. } & \multirow{2}{*}{$\begin{array}{l}\text { Exchange } \\
\text { Regime }\end{array}$} & \multicolumn{5}{|c|}{ Net Waitlist Upgrades\% } & \multicolumn{5}{|c|}{ Other Waitlist Additions\% } \\
\hline & & & $\mathbf{O}$ & $\mathbf{A}$ & $\mathbf{B}$ & $\mathbf{A B}$ & Total & $\mathbf{O}$ & $\mathbf{A}$ & $\mathbf{B}$ & AB & Total \\
\hline \multirow{9}{*}{$\mathbf{n}=\mathbf{3 0}$} & \multicolumn{12}{|l|}{ Waitlist $0 \%$} \\
\hline & All & None & 0 & 0 & 0 & 0 & $\overline{0}$ & 28.83 & 10.13 & 5.77 & 0.43 & 45.17 \\
\hline & All & Paired & 0 & 0 & 0 & 0 & 0 & 24.50 & 4.07 & 2.80 & 0.13 & 31.50 \\
\hline & Rational & TTC & 0 & 0 & 0 & 0 & 0 & 12.47 & 3.17 & 1.77 & 0.13 & 17.53 \\
\hline & Cautious & TTC & 0 & 0 & 0 & 0 & 0 & 13.77 & 3.17 & 1.87 & 0.13 & 18.93 \\
\hline & \multicolumn{12}{|l|}{ Waitlist $40 \%$} \\
\hline & All & Paired/Ind. & 9.10 & -6.33 & -1.23 & -1.53 & 0 & 14.67 & 2.20 & 1.37 & 0.07 & 18.30 \\
\hline & Rational & TTCC e & 5.13 & -2.47 & -1.07 & -1.60 & 0 & 7.13 & 1.17 & 0.63 & 0.00 & 8.93 \\
\hline & Cautious & TTCC e & 4.90 & -2.23 & $\begin{array}{l}-1.23 \\
\end{array}$ & -1.43 & 0 & 8.70 & 0.83 & 0.77 & 0.00 & 10.30 \\
\hline \multirow{9}{*}{$n=100$} & \multicolumn{12}{|l|}{ Waitlist 0\% } \\
\hline & All & None & 0 & 0 & 0 & 0 & 0 & 27.64 & 11.18 & 5.86 & 0.53 & 45.21 \\
\hline & All & Paired & 0 & 0 & 0 & 0 & 0 & 21.89 & 2.90 & 1.57 & 0.05 & 26.41 \\
\hline & Rational & TTC & 0 & 0 & 0 & 0 & 0 & 9.30 & 1.90 & 0.91 & 0.04 & 12.15 \\
\hline & Cautious & TTC & 0 & 0 & 0 & 0 & 0 & 9.78 & 2.00 & 0.95 & 0.04 & 12.77 \\
\hline & \multicolumn{12}{|l|}{ Waitlist $40 \%$} \\
\hline & All & Paired/Ind. & 8.25 & -5.27 & -1.70 & -1.28 & 0 & 13.42 & 1.62 & 1.08 & 0.05 & 16.17 \\
\hline & Rational & TTCC e & 3.49 & -1.17 & -1.07 & -1.25 & 0 & 5.71 & 0.46 & 0.42 & 0.01 & 6.60 \\
\hline & Cautious & TTCC e & 4.21 & -1.56 & -1.12 & -1.53 & 0 & 5.50 & 0.41 & 0.40 & 0.00 & 6.31 \\
\hline \multirow{9}{*}{$\mathrm{n}=\mathbf{3 0 0}$} & \multicolumn{12}{|l|}{ Waitlist 0\% } \\
\hline & All & None & 0 & 0 & 0 & 0 & 0 & 28.32 & 11.42 & 5.79 & 0.55 & 46.08 \\
\hline & All & Paired & 0 & 0 & 0 & 0 & 0 & 21.70 & 2.19 & 1.06 & 0.02 & 24.97 \\
\hline & Rational & TTC & 0 & 0 & 0 & 0 & 0 & 7.07 & 1.34 & 0.52 & 0.01 & 8.95 \\
\hline & Cautious & TTC & 0 & 0 & 0 & 0 & 0 & 7.23 & 1.37 & 0.52 & 0.01 & 9.14 \\
\hline & \multicolumn{12}{|l|}{ Waitlist $40 \%$} \\
\hline & All & Paired/Ind. & 8.40 & -5.65 & -1.42 & -1.32 & 0 & 13.21 & 1.36 & 0.63 & 0.01 & 15.21 \\
\hline & Rational & TTCC e & 2.77 & -0.87 & -0.63 & -1.27 & 0 & 4.28 & 0.23 & 0.18 & 0.00 & 4.69 \\
\hline & Cautious & TTCC e & 2.94 & -0.96 & -0.63 & -1.34 & 0 & 4.28 & 0.21 & 0.15 & 0.00 & 4.64 \\
\hline
\end{tabular}


Table 5: Properties of Cycles and W-chains for $n=30, n=100$, and $n=300$. Cycles of 1 pair length with an incompatible donor-patient pair are not counted.

\begin{tabular}{|c|c|c|c|c|c|c|c|c|c|c|}
\hline \multirow{3}{*}{$\begin{array}{l}\text { Pop. } \\
\text { Size }\end{array}$} & \multirow[t]{3}{*}{ Pref. } & \multirow{3}{*}{$\begin{array}{c}\text { Exchange } \\
\text { Regime }\end{array}$} & \multicolumn{4}{|c|}{ Cycles } & \multicolumn{4}{|c|}{ W-chains } \\
\hline & & & \multirow[t]{2}{*}{ Number } & \multicolumn{3}{|c|}{ Length (as pairs) } & \multirow[t]{2}{*}{ Number } & \multicolumn{3}{|c|}{ Length (as pairs) } \\
\hline & & & & Mean & Max. & Longest & & Mean & $\operatorname{Max}$ & Longest \\
\hline \multirow{9}{*}{$\mathbf{n}=\mathbf{3 0}$} & \multicolumn{10}{|l|}{ Waitlist $0 \%$} \\
\hline & All & None & $\begin{array}{l}16.45 \\
(2.69)\end{array}$ & $\begin{array}{c}1 \\
(0)\end{array}$ & $\begin{array}{c}1 \\
(0)\end{array}$ & 1 & $\begin{array}{c}0 \\
(0)\end{array}$ & - & - & - \\
\hline & All & Paired & $\begin{array}{l}18.50 \\
(2.46)\end{array}$ & $\begin{array}{c}1.11 \\
(0.08)\end{array}$ & $\begin{array}{c}1.90 \\
(0.30)\end{array}$ & 2 & $\begin{array}{c}0 \\
(0)\end{array}$ & - & - & - \\
\hline & Rational & TTC & $\begin{array}{l}14.65 \\
(2.22)\end{array}$ & $\begin{array}{c}2.95 \\
(0.43)\end{array}$ & $\begin{array}{c}5.65 \\
(1.15)\end{array}$ & 9 & $\begin{array}{c}0 \\
(0)\end{array}$ & - & - & - \\
\hline & Cautious & TTC & $\begin{array}{l}16.79 \\
(2.71)\end{array}$ & $\begin{array}{c}2.59 \\
(0.41)\end{array}$ & $\begin{array}{c}5.42 \\
(1.17)\end{array}$ & 10 & $\begin{array}{c}0 \\
(0)\end{array}$ & - & - & - \\
\hline & \multicolumn{10}{|l|}{ Waitlist $40 \%$} \\
\hline & All & Paired/Ind. & $\begin{array}{l}18.50 \\
(2.46)\end{array}$ & $\begin{array}{c}1.11 \\
(0.08)\end{array}$ & $\begin{array}{c}1.90 \\
(0.30)\end{array}$ & 2 & $\begin{array}{c}3.96 \\
(2.02)\end{array}$ & $\begin{array}{c}1 \\
(0)\end{array}$ & $\begin{array}{c}1 \\
(0)\end{array}$ & 1 \\
\hline & Rational & TTCC e & $\begin{array}{l}13.37 \\
(2.50)\end{array}$ & $\begin{array}{c}3.04 \\
(0.47)\end{array}$ & $\begin{array}{c}5.65 \\
(1.15)\end{array}$ & 9 & $\begin{array}{c}1.91 \\
(1.46)\end{array}$ & $\begin{array}{c}1.86 \\
(0.83)\end{array}$ & $\begin{array}{c}2.55 \\
(1.35)\end{array}$ & 7 \\
\hline & Cautious & TTCC e & $\begin{array}{l}15.74 \\
(2.75)\end{array}$ & $\begin{array}{c}2.62 \\
(0.44)\end{array}$ & $\begin{array}{c}5.42 \\
(1.17)\end{array}$ & 10 & $\begin{array}{c}1.84 \\
(1.32)\end{array}$ & $\begin{array}{c}1.81 \\
(0.68)\end{array}$ & $\begin{array}{c}2.26 \\
(1.01)\end{array}$ & 6 \\
\hline \multirow{9}{*}{$n=100$} & \multicolumn{10}{|l|}{ Waitlist $0 \%$} \\
\hline & All & None & $\begin{array}{l}54.79 \\
(4.48)\end{array}$ & $\begin{array}{c}1 \\
(0)\end{array}$ & $\begin{array}{c}1 \\
(0)\end{array}$ & 1 & $\begin{array}{c}0 \\
(0)\end{array}$ & - & - & - \\
\hline & All & Paired & $\begin{array}{l}64.19 \\
(4.33)\end{array}$ & $\begin{array}{c}1.15 \\
(0.03)\end{array}$ & $\begin{array}{c}2.00 \\
(0.00)\end{array}$ & 2 & $\begin{array}{c}0 \\
(0)\end{array}$ & - & - & - \\
\hline & Rational & TTC & $\begin{array}{l}36.53 \\
(3.44)\end{array}$ & $\begin{array}{c}4.22 \\
(0.41)\end{array}$ & $\begin{array}{l}10.14 \\
(1.65)\end{array}$ & 15 & $\begin{array}{c}0 \\
(0)\end{array}$ & - & - & - \\
\hline & Cautious & TTC & $\begin{array}{l}45.53 \\
(4.29)\end{array}$ & $\begin{array}{c}3.51 \\
(0.33)\end{array}$ & $\begin{array}{c}9.82 \\
(1.81)\end{array}$ & 17 & $\begin{array}{c}0 \\
(0)\end{array}$ & - & - & - \\
\hline & \multicolumn{10}{|l|}{ Waitlist $40 \%$} \\
\hline & All & Paired/Ind. & $\begin{array}{l}64.19 \\
(4.33)\end{array}$ & $\begin{array}{c}1.15 \\
(0.03)\end{array}$ & $\begin{array}{c}2.00 \\
(0.00)\end{array}$ & 2 & $\begin{array}{l}10.24 \\
(3.07)\end{array}$ & $\begin{array}{c}1 \\
(0)\end{array}$ & $\begin{array}{c}1 \\
(0)\end{array}$ & 1 \\
\hline & Rational & TTCC e & $\begin{array}{l}32.91 \\
(4.16) \\
\end{array}$ & $\begin{array}{c}4.41 \\
(0.43) \\
\end{array}$ & $\begin{array}{l}10.14 \\
(1.65) \\
\end{array}$ & 15 & $\begin{array}{c}3.96 \\
(1.97) \\
\end{array}$ & $\begin{array}{c}2.40 \\
(0.93) \\
\end{array}$ & $\begin{array}{c}3.96 \\
(1.97) \\
\end{array}$ & 11 \\
\hline & Cautious & TTCC e & $\begin{array}{l}42.00 \\
(5.43)\end{array}$ & $\begin{array}{c}3.61 \\
(0.39)\end{array}$ & $\begin{array}{c}9.82 \\
(1.81)\end{array}$ & 17 & $\begin{array}{c}4.72 \\
(2.60)\end{array}$ & $\begin{array}{c}2.17 \\
(0.65)\end{array}$ & $\begin{array}{c}3.76 \\
(1.64)\end{array}$ & 10 \\
\hline \multirow{9}{*}{$\mathbf{n}=\mathbf{3 0 0}$} & \multicolumn{10}{|l|}{$\overline{\text { Waitlist } 0 \%}$} \\
\hline & All & None & $\begin{array}{l}161.76 \\
(8.47)\end{array}$ & $\begin{array}{c}1 \\
(0)\end{array}$ & $\begin{array}{c}1 \\
(0)\end{array}$ & 1 & $\begin{array}{c}0 \\
(0)\end{array}$ & - & - & - \\
\hline & All & Paired & $\begin{array}{l}193.42 \\
(7.42)\end{array}$ & $\begin{array}{c}1.16 \\
(0.02)\end{array}$ & $\begin{array}{c}2.00 \\
(0.00)\end{array}$ & 2 & $\begin{array}{c}0 \\
(0)\end{array}$ & - & - & - \\
\hline & Rational & TTC & $\begin{array}{l}79.54 \\
(4.91)\end{array}$ & $\begin{array}{c}5.98 \\
(0.43)\end{array}$ & $\begin{array}{l}16.84 \\
(2.41)\end{array}$ & 26 & $\begin{array}{c}0 \\
(0)\end{array}$ & - & - & - \\
\hline & Cautious & TTC & $\begin{array}{l}102.14 \\
(7.00) \\
\end{array}$ & $\begin{array}{c}4.89 \\
(0.33) \\
\end{array}$ & $\begin{array}{l}16.00 \\
(2.00) \\
\end{array}$ & 22 & $\begin{array}{c}0 \\
(0) \\
\end{array}$ & - & - & - \\
\hline & \multicolumn{10}{|l|}{ Waitlist $40 \%$} \\
\hline & All & Paired/Ind. & $\begin{array}{l}193.42 \\
(7.42)\end{array}$ & $\begin{array}{c}1.16 \\
(0.02)\end{array}$ & $\begin{array}{c}2.00 \\
(0.00)\end{array}$ & 2 & $\begin{array}{l}29.30 \\
(5.18) \\
\end{array}$ & $\begin{array}{c}1 \\
(0) \\
\end{array}$ & $\begin{array}{c}1 \\
(0) \\
\end{array}$ & 1 \\
\hline & Rational & TTCC e & $\begin{array}{l}71.17 \\
(5.88) \\
\end{array}$ & $\begin{array}{c}6.30 \\
(0.46) \\
\end{array}$ & $\begin{array}{l}16.84 \\
(2.41) \\
\end{array}$ & 26 & $\begin{array}{c}9.05 \\
(4.07) \\
\end{array}$ & $\begin{array}{c}2.88 \\
(0.78) \\
\end{array}$ & $\begin{array}{c}6.47 \\
(2.40) \\
\end{array}$ & 15 \\
\hline & Cautious & TTCC e & $\begin{array}{l}93.76 \\
(7.51) \\
\end{array}$ & $\begin{array}{c}5.05 \\
(0.33)\end{array}$ & $\begin{array}{l}16.00 \\
(2.00)\end{array}$ & 22 & $\begin{array}{c}9.57 \\
(4.20)\end{array}$ & $\begin{array}{c}2.65 \\
(0.72) \\
\end{array}$ & $\begin{array}{c}5.99 \\
(2.23)\end{array}$ & 12 \\
\hline
\end{tabular}




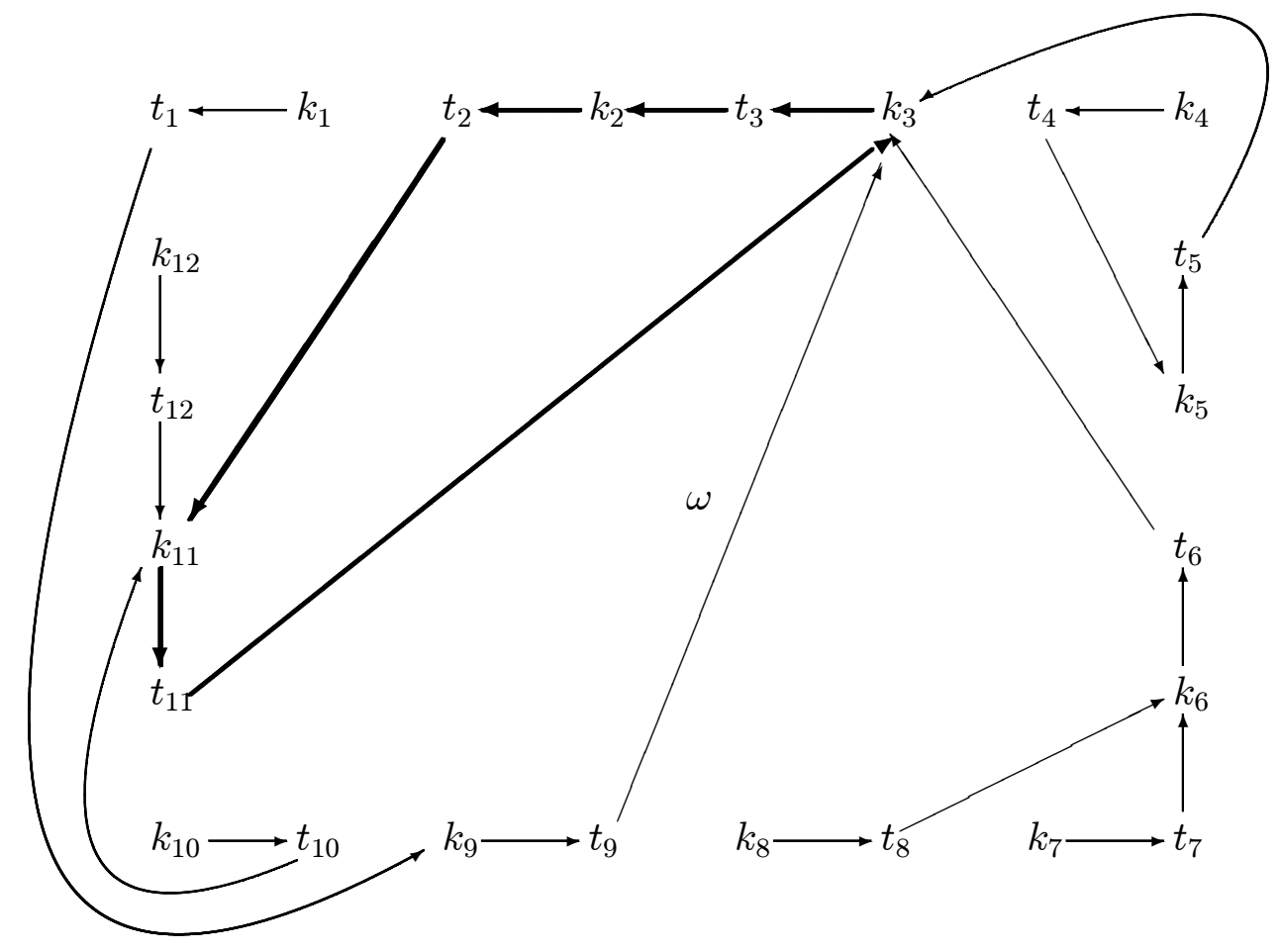

Figure 1: Example 1, Round 1. There is a single cycle $C_{1}=\left(k_{11}, t_{11}, k_{3}, t_{3}, k_{2}, t_{2}\right)$. Remove the cycle by assigning $k_{11}$ to $t_{2}, k_{3}$ to $t_{11}$, and $k_{2}$ to $t_{3}$. 


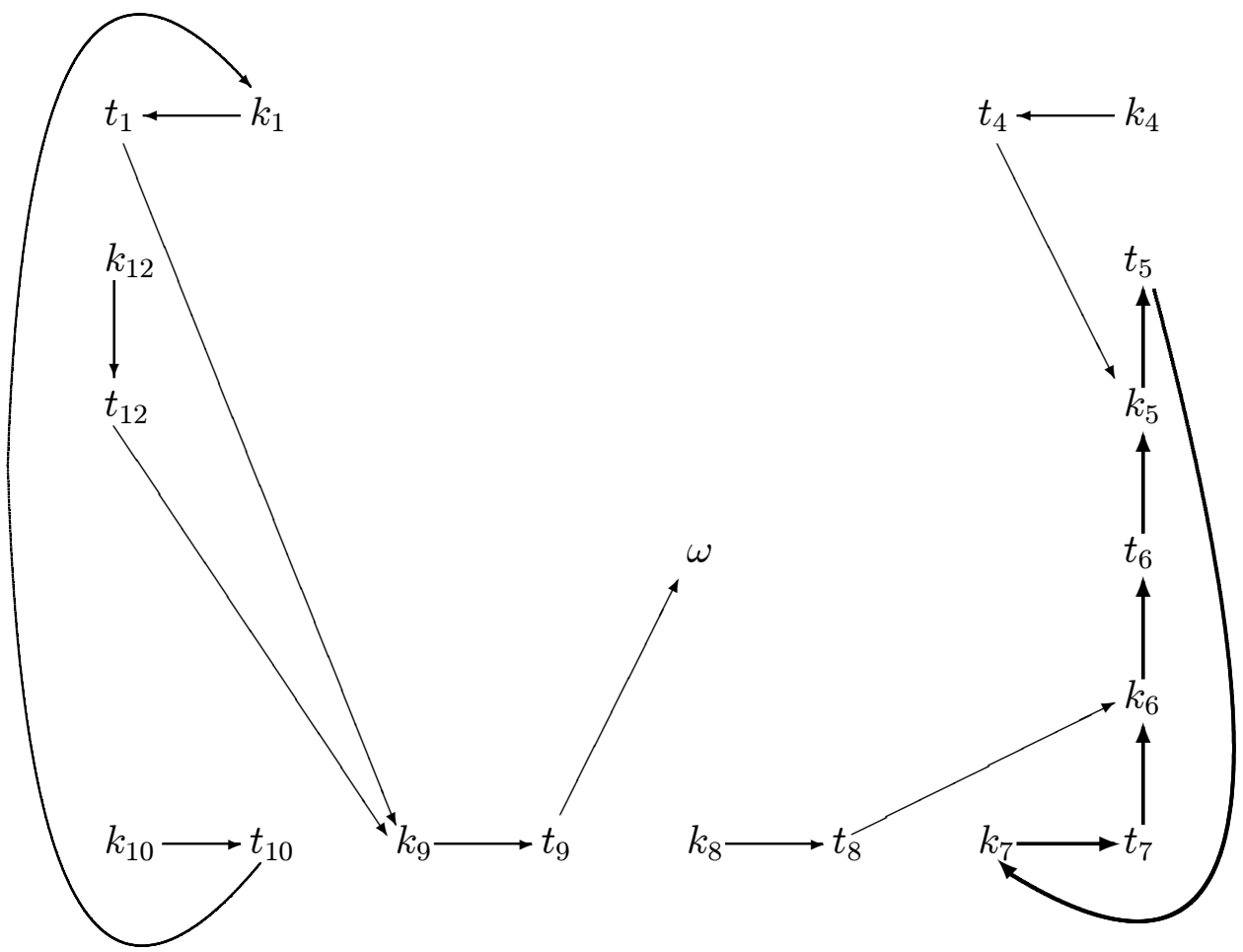

Figure 2: Example 1, Round 2. Upon removing cycle $C_{1}$, a new cycle $C_{2}=\left(k_{7}, t_{7}, k_{6}, t_{6}, k_{5}, t_{5}\right)$ forms. Remove it by assigning $k_{7}$ to $t_{5}, k_{6}$ to $t_{7}$, and $k_{5}$ to $t_{6}$. 


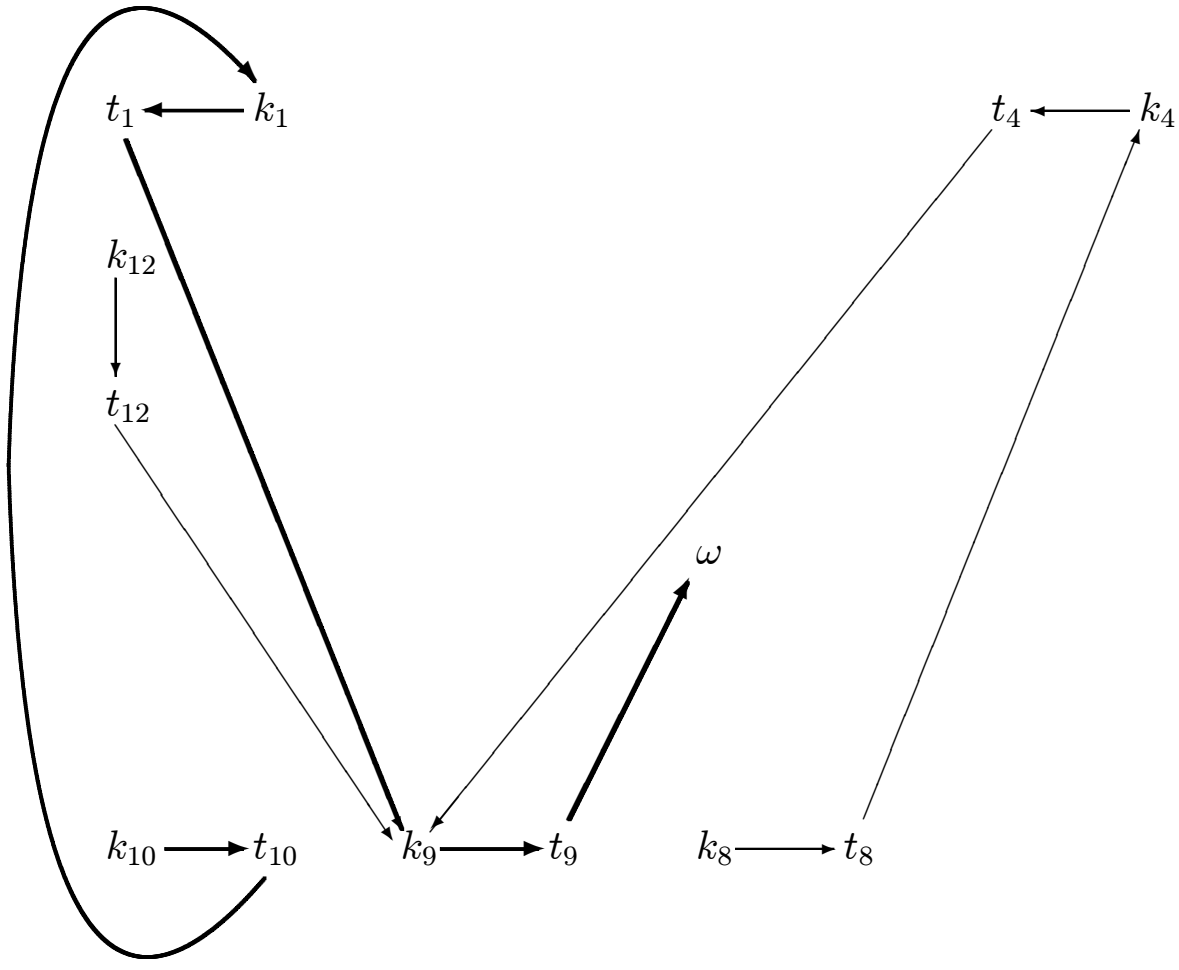

Figure 3: Example 1, Round 3. No new cycle forms and hence each kidney-patient pair starts a w-chain. The longest w-chains are $W_{1}=\left(k_{8}, t_{8}, k_{4}, t_{4}, k_{9}, t_{9}\right)$ and $W_{2}=\left(k_{10}, t_{10}, k_{1}, t_{1}, k_{9}, t_{9}\right)$. Since $t_{1}$, the highest priority patient, is in $W_{2}$ but not in $W_{1}$, choose and fix $W_{2}$. Assign $w$ to $t_{9}, k_{9}$ to $t_{1}$, and $k_{1}$ to $t_{10}$ but do not remove them. Kidney $k_{10}$, the kidney at the tail of $W_{2}$, remains available for the next round. 


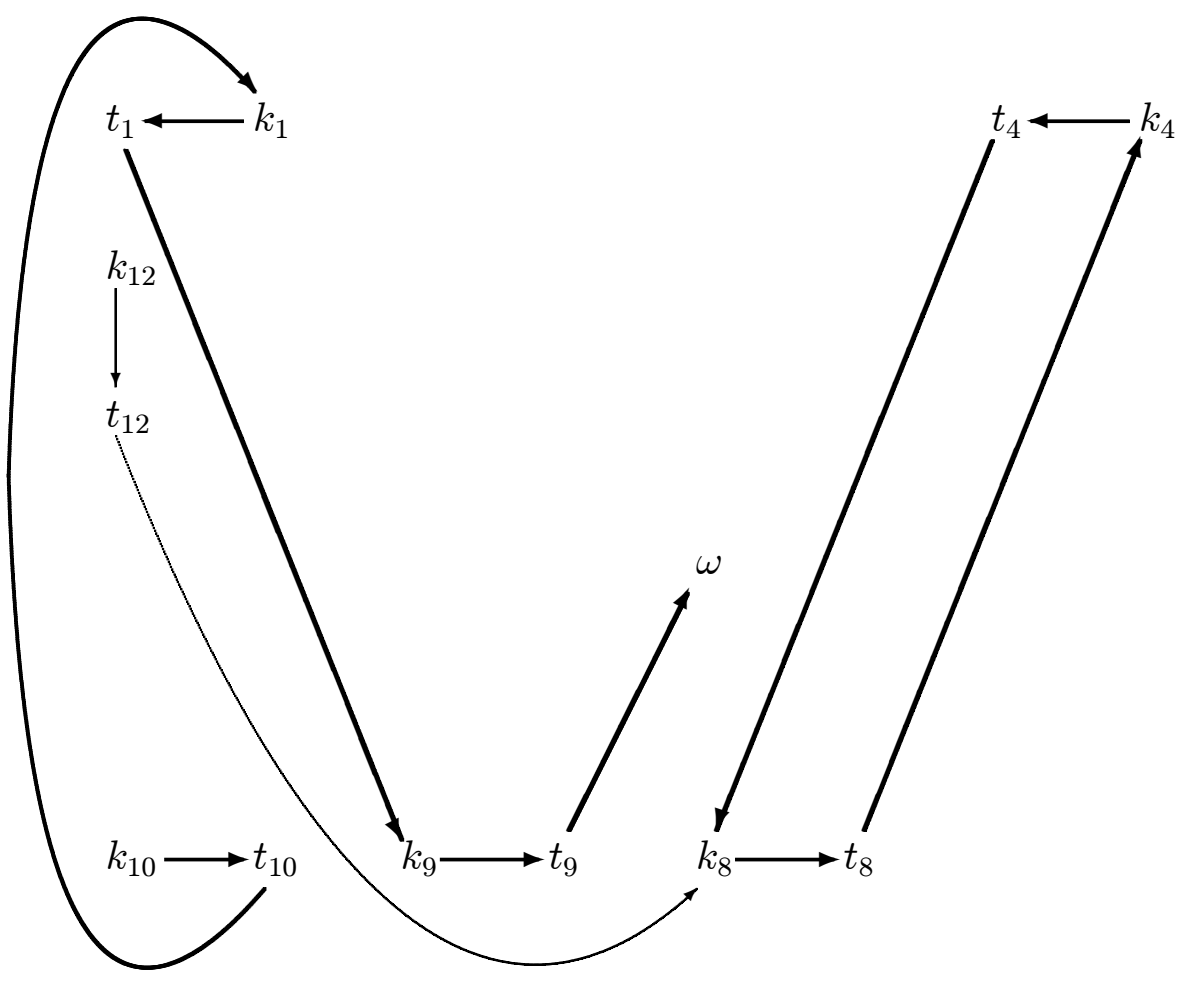

Figure 4: Example 1, Round 4. Upon fixing the w-chain $W_{2}$, a new cycle $C_{3}=\left(k_{4}, t_{4}, k_{8}, t_{8}\right)$ forms. Remove it by assigning $k_{4}$ to $t_{8}$ and $k_{8}$ to $t_{4}$. 


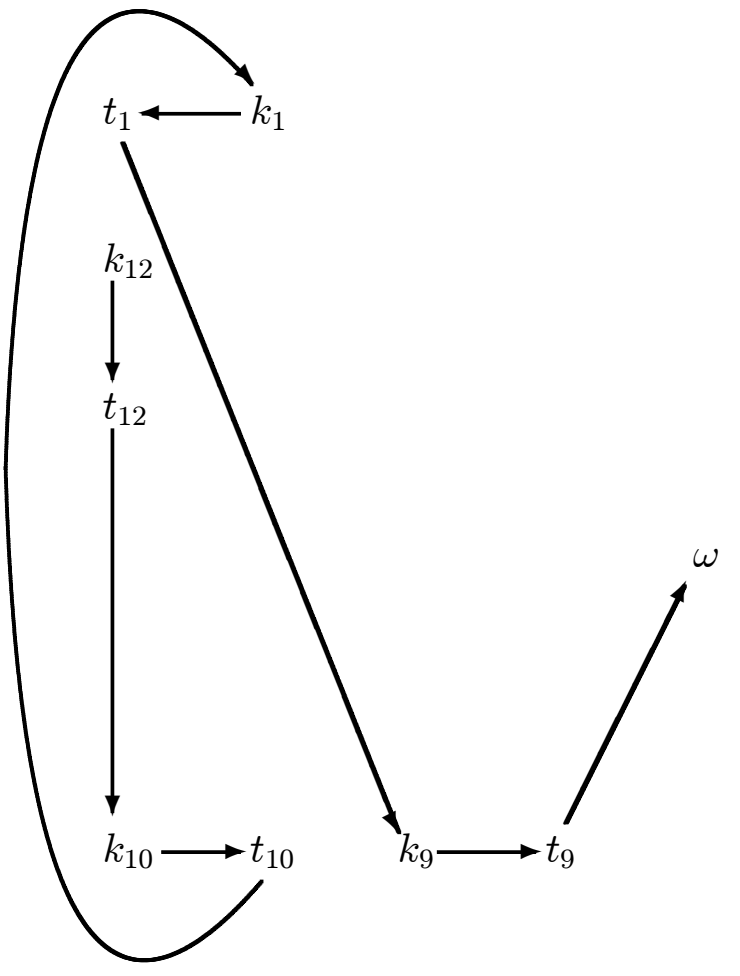

Figure 5: Example 1, Round 5. No new cycles form and the pair $\left(k_{12}, t_{12}\right)$ "joins" $W_{2}$ from its tail to form the longest w-chain $W_{3}=\left(k_{12}, t_{12}, k_{10}, t_{10}, k_{1}, t_{1}, k_{9}, t_{9}\right)$. Fix $W_{3}$ and assign $k_{10}$ to $t_{12}$. Since no patient is left, w-chain $W_{3}$ is removed and kidney $k_{12}$ at its tail is offered to the highest priority patient at the cadaveric waiting list. 